Purdue University Purdue e-Pubs

9-27-2005

\title{
Prediction of the Onset of Nucleate Boiling in Microchannel Flow
}

Dong Liu

Poh-Seng Lee

S V. Garimella

Purdue University, sureshg@purdue.edu

Follow this and additional works at: http://docs.lib.purdue.edu/coolingpubs

Liu, Dong; Lee, Poh-Seng; and Garimella, S V., "Prediction of the Onset of Nucleate Boiling in Microchannel Flow" (2005). CTRC Research Publications. Paper 8.

http://dx.doi.org/10.1016/j.ijheatmasstransfer.2005.07.021

This document has been made available through Purdue e-Pubs, a service of the Purdue University Libraries. Please contact epubs@purdue.edu for additional information. 


\title{
Prediction of the Onset of Nucleate Boiling in Microchannel Flow $\$$
}

\author{
Dong Liu, Poh-Seng Lee and Suresh V. Garimella ${ }^{\text {It }}$ \\ Cooling Technologies Research Center \\ School of Mechanical Engineering \\ Purdue University \\ West Lafayette, Indiana 47907-2088 USA
}

\begin{abstract}
The onset of nucleate boiling in the flow of water through a microchannel heat sink was investigated. The microchannels considered were $275 \mu \mathrm{m}$ wide by $636 \mu \mathrm{m}$ deep. Onset of nucleate boiling was identified with a high-speed imaging system and the heat flux at incipience was measured under various flow conditions. An analytical model was developed to predict the incipient heat flux as well as the bubble size at the onset of boiling. The closed-form solution obtained sheds light on the impact of the important system parameters on the incipient heat flux. The model predictions yield good agreement with the experimental data.
\end{abstract}

Keywords: Microchannels, electronics cooling, boiling, incipience, high heat flux, heat sink

$\S$ Submitted for possible publication in International Journal of Heat and Mass Transfer, January 2005, and in revised form, April 2005.

II Author to whom correspondence should be addressed: 765-494-5621; 765-494-0539 (fax); sureshg@purdue.edu 


\section{NOMENCLATURE}

$A_{b} \quad$ area of microchannel heat sink, $m^{2}$

$\mathrm{c}_{\mathrm{p}} \quad$ specific heat, $\mathrm{kJ} / \mathrm{kg}^{\circ} \mathrm{C}$

C shape factor

$\mathrm{D}_{\mathrm{h}} \quad$ hydraulic diameter, $\mu \mathrm{m}$

G mass flux, $\mathrm{kg} / \mathrm{s} \mathrm{m}^{2}$

$\mathrm{h}_{\mathrm{fg}} \quad$ latent heat, $\mathrm{J} / \mathrm{kg}$

$\mathrm{H}_{\mathrm{c}} \quad$ microchannel height, $\mu \mathrm{m}$

I current, A

$\mathrm{k}$ thermal conductivity, $\mathrm{W} / \mathrm{m}^{\circ} \mathrm{C}$

L channel length

n number of microchannels

$\mathrm{Nu} \quad$ Nusselt number

$\mathrm{p} \quad$ pressure, $\mathrm{Pa}$

q" applied heat flux, W/cm ${ }^{2}$

$\mathrm{q}_{\mathrm{w}}$, effective heat flux, $\mathrm{W} / \mathrm{cm}^{2}$

$\mathrm{r} \quad$ radius, $\mu \mathrm{m}$

Re Reynolds Number (based on channel

hydraulic diameter)

$\mathrm{T}$ temperature, ${ }^{\circ} \mathrm{C}$

$\mathrm{u}_{0} \quad$ fluid inlet velocity, $\mathrm{m} / \mathrm{s}$

V voltage, $\mathrm{V}$

$\mathrm{w}_{\mathrm{c}} \quad$ microchannel width, $\mu \mathrm{m}$ $\mathrm{w}_{\mathrm{w}} \quad$ microchannel fin thickness, $\mu \mathrm{m}$

$\mathrm{y}_{\mathrm{b}} \quad$ bubble height, $\mu \mathrm{m}$

\section{Greek symbols}

$\alpha \quad$ microchannel aspect ratio

$\phi \quad$ portion of the total power absorbed by

the water

$\eta \quad$ fin efficiency

$\theta \quad$ contact angle, deg

$\rho \quad$ density, $\mathrm{kg} / \mathrm{m}^{3}$

$\sigma \quad$ surface tension, $\mathrm{N} / \mathrm{m}$

\section{Subscripts}

b bubble

c cavity

f fluid

fd fully developed flow

in inlet

out outlet

min minimum

$\max$ maximum

s saturate

v vapor

w wall 


\section{INTRODUCTION}

Boiling and two-phase flow in microchannels has attracted increasing interest in recent years. Utilizing the latent heat of the coolant, two-phase microchannel heat sinks can dissipate much higher heat fluxes while requiring smaller rates of coolant flow than in the single-phase counterpart. Better temperature uniformity across the heat sink is also achievable. In spite of these attributes, the complex nature of convective flow boiling in microchannel heat sinks is still not well-understood, hindering their application in industry practice $[1,2,3,4]$. One subject of particular importance is the prediction of the onset of nucleate boiling (ONB) in microchannels. The first occurrence of vapor bubbles demarcates the transition from a single-phase to a two-phase flow regime, with the accompanying dramatic change in heat transfer and pressure drop. In addition, a prediction of the ONB is necessary for understanding other flow boiling phenomena such as the onset of significant void (OSV) and departure from nucleate boiling (DNB) [5].

A number of studies have been directed at understanding the ONB, with the majority considering conventional-sized channels. Table 1 summarizes analytical and semi-analytical studies from the literature $[6,7,8,9,10,11,12,13,14]$, including information on key assumptions, model development and incipient heat flux correlations proposed. Hsu [6] was the first to postulate a minimum superheat criterion for the ONB in pool boiling; he proposed that the bubble nucleus would grow only if the minimum temperature surrounding the bubble (the temperature at the tip of the bubble) is at least equal to the saturation temperature of the vapor inside the bubble. Following the same rationale, Bergles and Rohsenow [8] extended Hsu's model and proposed a graphical solution to predict the incipient heat flux in flow boiling. Sato and Matsumara [7] derived an analytical relationship for the incipient heat flux in terms of wall superheat. Davis and Anderson [9] provided an analytical treatment of the approach of Bergles and Rohsenow, and introduced the contact angle as a variable in the prediction of ONB. More recently, Kandlikar et al. [10] numerically computed the temperature at the location of the stagnation point around the bubble, which was used as the minimum temperature in the ONB criterion. Celata et al. [11] investigated the onset of subcooled boiling in the forced convective flow of water and recommended 
Thom's correlation [15] for its good match with the experimental data. Basu et al. [12] postulated the dependence of the available cavity size on the contact angle and proposed a correlation for the incipient heat flux.

Fewer studies have considered the ONB in microchannels. Ghiaasiaan and Chedester [5] proposed a semi-empirical method to predict the ONB in turbulent flow in microtubes. Qu and Mudawar [13] measured the incipient boiling heat flux in a microchannel heat sink and developed a mechanistic model to incorporate both mechanical and thermal considerations. Li and Cheng [14] employed nucleation kinetics to derive the wall superheat at the ONB, and included a consideration of the effects of contact angle, dissolved gas, and the existence of microcavities and corners in the microchannels on ONB.

Most past studies of ONB have been based on the minimum superheat criterion of Hsu. However, Hsu's model was developed for pool boiling and did not incorporate features of convective flow boiling, especially the influence on heat flux of both the wall and fluid temperatures. In the early models, therefore, convective heat transfer was either ambiguously incorporated $[7,8,9]$ or required graphical or numerical procedures to derive the ONB criterion $[10,13,14]$. An analytical model which captures essential characteristics of forced convective flow is not available for predicting the ONB in microchannels.

The present study is aimed at experimentally identifying the onset of nucleate boiling in forced convective flow in a microchannel heat sink. An analytical model with a closed-form solution is developed to represent the thermodynamics of bubble nucleation as well as the convective nature of flow boiling in microchannels. The effects of fluid inlet subcooling, wall boundary conditions and microchannel geometry are incorporated in the model. Model predictions are validated against the experimental results obtained.

\section{EXPERIMENTS}

\subsection{Experimental Setup}


Figure 1(a) shows the test loop constructed to investigate convective boiling in microchannels. A variable-speed gear pump is used to circulate the working fluid (deionized water) through the test loop. A $7-\mu \mathrm{m}$ filter is included upstream of the microchannels. Two turbine flowmeters are arranged in parallel to measure flow rates at the high and low ranges in the tests. A pre-heater with a temperature control module adjusts the degree of subcooling in the fluid prior to entering the microchannel heat sink. A liquid-to-air heat exchanger is utilized to condense the vapor in the two-phase mixture before the fluid flows back to the reservoir. The pressure in the entrance and exit manifolds of the microchannel test section is measured with absolute pressure transducers. The experimental data are read into a data acquisition system for processing.

The microchannel test section consists of a copper test block, an insulating G10 housing piece and a G7 fiberglass cover, as shown in Fig. 1(b). Twenty-five microchannels were cut into the top surface of the copper block with a footprint of $25.4 \mathrm{~mm} \times 25.4 \mathrm{~mm}$ using a precision sawing technique. The microchannel measures $275 \mu \mathrm{m}$ in width $\left(\mathrm{w}_{\mathrm{c}}\right)$ and $636 \mu \mathrm{m}$ in height $\left(\mathrm{H}_{\mathrm{c}}\right)$, with a fin thickness $\left(\mathrm{w}_{\mathrm{w}}\right)$ of $542 \mu \mathrm{m}$. Holes were drilled into the bottom of the copper block to house eight cartridge heaters that can provide a combined maximum power input of $1600 \mathrm{~W}$. As indicated in Fig. 1(c), three copper-constantan (Type- $\mathrm{T}$ ) thermocouples $\left(\mathrm{T}_{1}\right.$ through $\mathrm{T}_{3}$ ) made from 36-gauge wire were placed along the microchannel length at $1.02 \mathrm{~cm}$ intervals. These thermocouples are installed at a distance of $3.17 \mathrm{~mm}$ from the base of the microchannels, and temperature readings are extrapolated to provide the microchannel wall temperatures at three streamwise locations. Four axial thermocouples $\left(\mathrm{T}_{4}\right.$ through $\left.\mathrm{T}_{7}\right)$ were embedded in the copper block at $6.35 \mathrm{~mm}$ axial intervals for measurement of the average heat flux. The inlet and outlet fluid temperatures $\left(\mathrm{T}_{\mathrm{f}, \text { in }}\right.$ and $\left.\mathrm{T}_{\mathrm{f}, \mathrm{out}}\right)$ were obtained using two thermocouples positioned immediately upstream and downstream of the microchannels, respectively. A glass viewing window is sandwiched between the G7 cover and the G10 housing for visualization of the boiling process. The voltage input to the cartridge heaters was controlled by a DC power supply unit. The power supplied was calculated using the measured voltage and current (measured by means of a shunt resistor) supplied to the heaters. 


\subsection{High-speed Imaging}

A high-speed imaging system was employed to visualize the bubble dynamics upon the initiation of nucleate boiling in the microchannels. An ultra-high speed camera was used for image capturer, with a frame rate of 2,000 frames per second (fps) at the full resolution of $1024 \times 1024$ pixels, and a maximum frame rate of 120,000 fps at reduced resolution along one dimension. A microscope with a number of objective lenses was employed to achieve high magnification and a dynamic range of working distance. A high-power illumination source was used to compensate for the short exposure time necessitated by the very-high shutter speed.

\subsection{Test Procedure}

Prior to each experiment run, the working fluid was degassed by evacuating the reservoir to -1 bar and violently boiling the water for approximately one hour. The amount of dissolved gas in the water was monitored in the experiments with an in-line oxygen sensor. The concentration was found to be less than 4 ppm such that the effects of dissolved gas are negligible on the boiling heat transfer [16].

To initiate an experiment, the gear pump is first turned on and the flow rate is adjusted to the desired value. The preheater and temperature controller are then powered up and the fluid inlet temperature set to the required degree of subcooling. After the fluid inlet temperature is stabilized, the heater power supply is switched on and set to the desired value. A steady state was reached in approximately 30 minutes, identified as the state when readings from all thermocouples remained unchanged (within $\pm 0.1^{\circ} \mathrm{C}$ ) over a two-minute period. At this time, the flow rate, temperature, pressure and power input values are stored using the data acquisition system. Each steady-state value was calculated as an average of 300 readings. The heat flux is then increased in small increments for additional tests, and this procedure repeated. The flow pattern is also visualized and recorded near the exit of the microchannels using the high-speed imaging system throughout the course of each experiment. When the first set of bubbles appears in the microchannels, nucleate boiling is deemed to have been initiated and the corresponding heat flux at which this occurs recorded as the incipient heat flux. 


\subsection{Uncertainty}

The total power provided to the cartridge heaters was determined from the product of the voltage and the current across the cartridge heater, $\mathrm{V}$ and I. The heat loss to the ambient from the copper block is estimated from the sensible heat gain by the fluid under single-phase heat transfer conditions:

$$
q=\rho_{f} c_{p} Q\left(T_{f, \text { out }}-T_{f, \text { in }}\right)
$$

The density and specific heat are calculated based on the mean fluid temperature $T_{m}$ (average of the fluid inlet and outlet temperatures). Once boiling inception has occurred, over all the experiments, $80 \sim 98 \%$ of the input power was transferred to the water, depending on the heat flux and flow rate. The applied heat flux q"' is, therefore, defined as

$$
q^{\prime \prime}=\phi V I / A_{b}
$$

where $\phi$ is the portion of the total power absorbed by the water; $A_{b}$ is the base area of the copper block, $\mathrm{W} \cdot \mathrm{L}$. The heat input can also be determined from the temperature gradient measured with the axial thermocouples. The difference between the heat input measured by this means differed from the sensible heat gain by at most $5 \%$ upon boiling inception. The uncertainties associated with the voltage and current measurements were $0.0035 \%$ and $0.5 \%$, respectively. A standard error analysis [17] revealed uncertainties in the reported heat flux in the range of 2 to $6 \%$. The uncertainty in temperature measurements was $\pm 0.3^{\circ} \mathrm{C}$ with the T-type thermocouples employed. The flow meter was calibrated with a weighting method, yielding a maximum uncertainty of $2.4 \%$. The measurement error for the pressure transducer was $0.25 \%$ of full scale $(1 \mathrm{~atm})$. Uncertainty associated with the measurement of bubble radius from the digital images was 3 pixels, with an object-to-image ratio of $1.28 \mu \mathrm{m} /$ pixel, which translates to $\pm 3.84 \mu \mathrm{m}$. Experiments conducted over a period of months showed good repeatability.

\section{ANALYTICAL MODEL}

\subsection{Assumptions}

The important assumptions in the present analysis, following the treatment in [9], are: 
1) The bubble nucleus takes the shape of a truncated sphere when it develops at a surface cavity [18], as depicted in Fig. 2(a);

2) The bubble nucleus does not alter the temperature profile in the surrounding single-phase fluid because of its extremely small size;

3) The vapor and liquid phases are in equilibrium under saturated conditions;

A bubble nucleus will grow if the temperature of the fluid at a distance from the wall equal to the bubble height is greater than the superheat requirement.

\subsection{Bubble Superheat Equation}

Equilibrium theory provides the superheat equation for the bubble nucleus:

$$
T_{b}-T_{s}=T_{b} \frac{2 \sigma}{\rho_{v} h_{f g} r_{b}}
$$

where $T_{s}\left(p_{f}\right)$ is written as $T_{s}$ for brevity, and $r_{b}$ is the bubble radius. It may be noted that Eq. (11) differs

in an important detail from the superheat equation generally used in the literature $\left(T_{b}-T_{s}=T_{s} \frac{2 \sigma}{\rho_{v} h_{f g} r_{b}}\right)$.

A detailed derivation of Eq. (11), which shows that the temperature on the right hand side should be $\mathrm{T}_{\mathrm{b}}$ (and not $\mathrm{T}_{\mathrm{s}}$ ) is included in the Appendix.

From Fig. 2(a), the following geometric relations are evident:

$$
\begin{aligned}
& y_{b}=r_{b}(1+\cos \theta) \\
& r_{c}=r_{b} \sin \theta
\end{aligned}
$$

The superheat equation, Eq. (11), can then be written as

$$
T_{b}-T_{s}=T_{b} \frac{2 \sigma C}{\rho_{v} h_{f g} y_{b}}
$$

where $\mathrm{C}$ is the shape factor, $C=1+\cos \theta$. This equation describes the superheat criterion for the onset of nucleate boiling. Rearrangement of Eq. (14) yields the vapor temperature 


$$
T_{b}=T_{s} /\left(1-\frac{2 \sigma C}{\rho_{v} h_{f g} y_{b}}\right)
$$

\subsection{Fluid Temperature}

The temperature of the fluid surrounding the bubble nucleus can be obtained from single-phase heat transfer following assumption 2 in section 3.1 above. In the vicinity of the channel surface, bulk convection is adequately damped out so that a linear profile can be assumed for the fluid temperature in this region:

$$
T_{f}(y)=T_{w}-q_{w} " y / k_{f}
$$

Explicitly relating the wall temperature $\mathrm{T}_{\mathrm{w}}$ to the effective wall heat flux $\mathrm{q}^{\prime \prime}$ in Eq. (16) allows for convective heat transfer features to be represented in the model, unlike in past work.

Since uniform heat flux is the most common boundary condition encountered in electronics cooling applications, the fluid temperature is sought under such boundary conditions in microchannel flow. It is therefore expected that the maximum fluid temperature would occur at the channel exit where the ONB will first be initiated. For a given fluid inlet velocity and temperature, the bulk mean temperature at the channel exit is derived from energy balance as

$$
T_{f, \text { out }}=T_{f, \text { in }}+\frac{q^{\prime \prime} W L}{\rho_{f} c_{p} u_{0}\left(n w_{c} H_{c}\right)}
$$

Assuming that convective heat transfer occurs uniformly along the channel surfaces (bottom and side walls) and that the flow is fully developed, the channel wall temperature is

$$
T_{w}=T_{f}+\frac{q_{w}{ }^{\prime \prime}}{\left(N u_{f d, 3} k_{f}\right) / D_{h}}
$$

in which the Nusselt number for fully-developed flow in a three-sides heated rectangular channel [19] is given by

$$
N u_{f d, 3}=8.235\left(1-1.883 / \alpha+3.767 / \alpha^{2}-5.814 / \alpha^{3}+5.361 / \alpha^{4}-2 / \alpha^{5}\right)
$$

and the effective wall heat flux q" is 


$$
q_{w}^{\prime \prime}=\frac{\phi V I}{n\left(w_{c}+2 \eta H_{c}\right) L}
$$

where $\mathrm{n}$ is the number of microchannels and $\eta$ is the fin efficiency. The effective wall heat flux q" related to the applied heat flux q"' as [20]

$$
q_{w} "=\left(\frac{\alpha}{1+2 \eta \alpha} \frac{w_{c}+w_{w}}{H_{c}}\right) q^{\prime \prime}
$$

Knowing the wall temperature $\mathrm{T}_{\mathrm{w}}$ and the effective wall heat flux $\mathrm{q}^{\prime \prime}$, the fluid temperature in the nearwall region can be calculated from Eq. (16).

\subsection{Onset of Nucleate Boiling}

Nucleate boiling may occur only when $T_{f} \geq T_{b}$ at the tip of the bubble nucleus, as shown in Fig.

2(b). From Eqs. (15) and (16), the necessary condition for ONB can be written as,

$$
T_{w}-\frac{q_{w}^{\prime \prime}}{k_{f}} y_{b}=T_{s} /\left(1-\frac{2 \sigma C}{\rho_{v} h_{f g} y_{b}}\right)
$$

Equation (22) can further be rearranged in terms of $y_{b}$

$$
\frac{q_{w} "}{k_{f}} y_{b}^{2}-\left(T_{w}+\frac{2 \sigma C}{\rho_{v} h_{f g}} \frac{q_{w} "}{k_{f}}-T_{s}\right) y_{b}+\frac{2 \sigma C}{\rho_{v} h_{f g}} T_{w}=0
$$

Solution of this equation yields

$$
y_{b}=\frac{\left(T_{w}+\frac{2 \sigma C}{\rho_{v} h_{f g}} \frac{q_{w} "}{k_{f}}-T_{s}\right) \pm \sqrt{\left(T_{w}+\frac{2 \sigma C}{\rho_{v} h_{f g}} \frac{q_{w} "}{k_{f}}-T_{s}\right)^{2}-4 \frac{2 \sigma C}{\rho_{v} h_{f g}} \frac{q_{w} "}{k_{f}} T_{w}}}{2 \frac{q_{w}{ }^{\prime \prime}}{k_{f}}}
$$

For both roots to be real, the determinant in Eq. (24) must be positive, i.e.,

$$
\left(T_{w}+\frac{2 \sigma C}{\rho_{v} h_{f g}} \frac{q_{w} "}{k_{f}}-T_{s}\right)^{2}-4 \frac{2 \sigma C}{\rho_{v} h_{f g}} \frac{q_{w} "}{k_{f}} T_{w} \geq 0
$$

The superheat criterion can be obtained by rearranging this inequality 


$$
\sqrt{T_{w}}-\sqrt{T_{s}} \geq \sqrt{\frac{2 \sigma C}{\rho_{v} h_{f g}} \frac{q_{w} "}{k_{f}}}
$$

It may be noted that the wall temperature $\mathrm{T}_{\mathrm{w}}$ is related to the wall heat flux $\mathrm{q}^{\prime \prime}$ by Eq. (16).

Several interesting observations may be drawn from Eq. (26) as follows.

1) For given conditions, i.e., wall heat flux $\mathrm{q}_{\mathrm{w}}$ ", fluid inlet velocity $\mathrm{u}_{0}$ and temperature $\mathrm{T}_{\mathrm{f}, \mathrm{in}}$, the measured wall temperature $T_{w}$, or a value of $T_{w}$ obtained from Eq. (18), may be substituted in the inequality (26) to determine if ONB will occur.

2) Conversely, if the fluid inlet conditions are prescribed and the heat flux allowed to vary, the threshold heat flux required to trigger the ONB can be predicted from the following equation:

$$
\sqrt{T_{f, i n}+\frac{q^{\prime \prime} W L}{\rho_{f} c_{p} u_{0}\left(n w_{c} H_{c}\right)}+\frac{\left(\frac{\alpha}{1+2 \eta \alpha} \frac{w_{c}+w_{w}}{H_{c}}\right) q^{\prime \prime}}{\left(N u_{f d, 3} k_{f}\right) / D_{h}}}-\sqrt{T_{s}}=\sqrt{\frac{2 \sigma C}{\rho_{v} h_{f g}} \frac{\left(\frac{\alpha}{1+2 \eta \alpha} \frac{w_{c}+w_{w}}{H_{c}}\right) q^{\prime \prime}}{k_{f}}}
$$

3) In some applications, it may be desirable to ensure the maintenance of single-phase flow in the microchannels. For such applications, it is clear that the onset of boiling can be delayed or avoided by requiring the fluid inlet velocity $\mathrm{u}_{0}$ to exceed a minimum value, or maintaining the inlet temperature $\mathrm{T}_{\mathrm{f}, \mathrm{in}}$ below a maximum. Both limits for such practical design guidelines may be calculated from Eq. (27).

\section{RESULTS AND DISCUSSION}

\subsection{Incipient Heat Flux}

When the incipient heat flux is reached in the experiments, a single bubble or a few bubbles could be observed simultaneously using the high-speed imaging system either close to the exit, or even further upstream, in several microchannels. These bubbles were usually observed to form near but not exactly at the edges (corners) on the channel bottom surface, as shown in Fig. 3. This is in accordance with the observation of Qu and Mudawar [13]. Table 2 lists the measured incipient heat flux for various fluid inlet velocities and temperatures. It indicates that the incipient heat flux increases with increased fluid inlet 
velocity while decreasing with increased inlet temperature. Figure 4(a) shows a comparison of the model predictions (Eq. (27)) with the measured incipient heat flux values from the present study. The model predictions agree well (to within 20\%) with the experiments (mean deviation of $9.6 \%$ and rms deviation of $1.2 \%$ ). Similar agreement was also seen in Fig. 4(b) when the predictions were compared against the experiments in [13]. However, the model predictions are seen in Fig. 4(a) to generally exceed the measured values. This may be explained by the fact that the local heat flux is not distributed uniformly across the channel surface as approximated in the model (Eq. (21)). Instead, it is relatively lower in the near-corner region $[13,21,22]$. The smaller temperature gradient will lead to a greater fluid temperature in this region than calculated by Eq. (16). As a consequence, the superheat equation (15) may be satisfied at a slightly lower applied heat flux than the model prediction.

To complement the incipient heat flux results identified from the visualization approach, the microchannel wall temperatures and pressure drop along the microchannels were analyzed. The ONB is identified from these measurements as the point at which deviations from single-phase behavior is observed as a sudden change in slope of temperature and pressure drop versus the heat flux. Values of the incipient heat flux obtained by this independent method are also listed in Table 2, and are seen to be in good agreement with the visualization approach.

\subsection{Contact Angle}

The static contact angle $\theta$ has been employed as a parameter in previous ONB models. Since this parameter was not directly measured in experiments, a value for contact angle was somewhat arbitrarily assumed in these models. For instance, a hemispherical bubble nucleus ( $\theta=90 \mathrm{deg}$ ) was assumed in [5, 8, and 9], while a spherical bubble nucleus $(\theta=180 \mathrm{deg})$ was assumed in [7]. Contact angles of 30 and $80 \mathrm{deg}$ were assumed in [13] and only a weak dependence of the predicted incipient heat flux was noted on the value of the contact angle assumed.

In the present predictions, a contact angle of 90 deg was adopted. This is a physically reasonable assumption since the bubble is seen to remain on the mouth of a nucleation cavity after inception as it 
grows, until its detachment from the surface. During the course of this process, the contact angle decreases from its initial value to a minimum attained at bubble departure. In the absence of accurate measurements of contact angle (and incorporation into a model of the contact angle as a function of the growth process), the selection of a larger value of approximately 90 deg represents the boiling physics adequately. This choice is also supported by measurement of Shakir and Thome [23], who showed the contact angle for water/copper contact to be $86 \mathrm{deg}$.

The effect of the choice of contact angle on the predicted incipient heat flux was also examined further for Case $1\left(u=0.52 \mathrm{~m} / \mathrm{s}\right.$ and $\left.T_{f, \text { in }}=84.9^{\circ} \mathrm{C}\right)$. The predicted incipient heat flux decreased slightly as the contact angle assumed in the model was increased from 30 to $90 \mathrm{deg}$. This is not surprising because, for a given surface (characterized by cavity size $r_{c}$ shown in Fig. 2 (a)), a smaller contact angle corresponds to a larger bubble size which would need more heat to satisfy the superheat criterion. However, the change in predicted incipient flux over this range of contact angles was only by $8.6 \%$, and the choice of contact angle does not substantially impact the predictions.

\subsection{Wall Superheat}

From the inequality (26), the wall superheat can be written as

$$
T_{w}-T_{s}=\frac{2 \sigma C}{\rho_{v} h_{f g}} \frac{q_{w} "}{k_{f}}+2 \sqrt{T_{s}} \sqrt{\frac{2 \sigma C}{\rho_{v} h_{f g}} \frac{q_{w}{ }^{\prime \prime}}{k_{f}}}
$$

Substitution in Eq. (21) leads to

$$
T_{w}-T_{s}=\frac{2 \sigma C}{\rho_{v} h_{f g} k_{f}}\left(\frac{\alpha}{1+2 \eta \alpha} \frac{w_{c}+w_{w}}{H_{c}}\right) q "+2 \sqrt{T_{s}} \sqrt{\frac{2 \sigma C}{\rho_{v} h_{f g} k_{f}}\left(\frac{\alpha}{1+2 \eta \alpha} \frac{w_{c}+w_{w}}{H_{c}}\right) q^{\prime \prime}}
$$

Interestingly, Eq. (29) may be considered as a correction to Eq. (4) in [9]; for rectangular channels the equation from [9] takes the form:

$$
T_{w}-T_{s}=2 \sqrt{T_{s}} \sqrt{\frac{2 \sigma C}{\rho_{v} h_{f g} k_{f}}\left(\frac{\alpha}{1+2 \eta \alpha} \frac{w_{c}+w_{w}}{H_{c}}\right) q^{\prime \prime}}
$$


A comparison of predictions from Eq. (29) with those from other models in the literature [6-11] is shown in Fig. 5. Predictions from the present work are seen to agree very well with past models, except for those of Hsu [6] and Celata et al. [11]. The best match is with the work of Davis and Anderson [9], indicating that the additional term which arises in Eq. (29) above has only a secondary contribution to the numerical value of wall superheat predicted.

\subsection{Incipient Bubble Radius}

Figure 2(b) illustrates that the superheat criterion is satisfied only in the region $y_{b, \text { min }} \leq y_{b} \leq y_{b, \text { max }}$, where $\mathrm{y}_{\mathrm{b}, \text { min }}$ and $\mathrm{y}_{\mathrm{b}, \max }$ are defined by the two roots of Eq. (23), respectively.

Considering the geometric relation shown in Fig. 2(a), this requirement suggests that a cavity with radius $r_{c}$ could be active [6] only if,

$$
r_{c, \min } \leq r_{c} \leq r_{c, \max }
$$

where,

$$
\begin{gathered}
r_{c, \text { min }}=r_{c}^{*}-\frac{\sqrt{\left(T_{w}+\frac{2 \sigma C}{\rho_{v} h_{f g}} \frac{q_{w}{ }^{\prime \prime}}{k_{f}}-T_{s}\right)^{2}-4 \frac{2 \sigma C}{\rho_{v} h_{f g}} \frac{q_{w}{ }^{\prime \prime}}{k_{f}} T_{w}}}{2 \frac{q_{w}{ }^{\prime \prime}}{k_{f}}} \frac{\sin \theta}{1+\cos \theta} \\
r_{c, \text { max }}=r_{c}^{*}+\frac{\sqrt{\left(T_{w}+\frac{2 \sigma C}{\rho_{v} h_{f g}} \frac{q_{w}{ }^{\prime \prime}}{k_{f}}-T_{s}\right)^{2}-4 \frac{2 \sigma C}{\rho_{v} h_{f g}} \frac{q_{w}{ }^{\prime \prime}}{k_{f}} T_{w}}}{2 \frac{q_{w}}{k_{f}}} \frac{\sin \theta}{1+\cos \theta} \\
r_{c}^{*}=\frac{\left(T_{w}+\frac{2 \sigma C}{\rho_{v} h_{f g}} \frac{q_{w}{ }^{\prime \prime}}{k_{f}}-T_{s}\right)}{2 \frac{q_{w}{ }^{\prime \prime}}{k_{f}}} \frac{\sin \theta}{1+\cos \theta}
\end{gathered}
$$

The distribution of cavity sizes was not characterized in the present study, but the critical cavity size $r_{c}{ }^{*}$ and the range of active cavity sizes can be examined through Eqs. (32) to (34). Immediately upon the onset of nucleate boiling, $r_{c, \text { min }}$ and $r_{c, \text { max }}$ will reduce to $r_{c}{ }^{*}$, implying that only cavities of this specific 
size will be activated. However, temperature perturbations, particularly in microchannel heat sinks which contain multiple flow paths, lead to fluctuations in the wall temperature around the value required by the wall superheat equation (28). As was illustrated in Fig. 2(b), a slight temperature increase above the tangency condition would broaden the size range of active cavities and promote cavities within that range into nucleation sites. This is further demonstrated in Fig. 6(a) in which active cavity sizes for flow conditions of Case 4 in Table 2 are shown. The active cavity radius is seen to be strongly dependent on the wall temperature, varying from a critical value of $16.7 \mu \mathrm{m}$ to a range of values from $10 \mu \mathrm{m}$ to 23.2 $\mu \mathrm{m}$ for a small increase of $0.27^{\circ} \mathrm{C}$ in the wall temperature.

The incipient bubble radius $r_{b}$ can be derived from Eq. (34)

$$
r_{b}=\frac{r_{c}^{*}}{\sin \theta}
$$

for which the corresponding extreme values are:

$$
\begin{aligned}
& r_{b, \text { min }}=\frac{r_{c, \text { min }}}{\sin \theta} \\
& r_{b, \text { max }}=\frac{r_{c, \text { max }}}{\sin \theta}
\end{aligned}
$$

For several test cases in Table 1, the calculated incipient bubble radii are plotted in Fig. 6(b). The incipient bubble radius is seen to decrease slightly as the fluid velocity increases. More importantly, Fig. 6(b) provides the range of bubble radius that may be visualized in the experiment, as predicted by Eqs. (36) and (37), corresponding to a temperature variation of $\pm 0.3^{\circ} \mathrm{C}$, which is the thermocouple measurement uncertainty. For instance, the effective incipient bubble radius for Case 4 varies from 10 $\mu \mathrm{m}$ to $23.2 \mu \mathrm{m}$, instead of a single value of $16.7 \mu \mathrm{m}$. Bubbles in this full size range may be observed upon the ONB. This helps explain the observed lack of uniformity of bubble size upon the onset of boiling.

Very limited data $[24,25]$ were available in the past literature on experimental measurement of ONB bubble radius, due to the inadequacy of visualization capabilities. In the present work, using the 
high-speed imaging system, boiling visualization was conducted with much improved spatial and temporal resolution to study the ONB in microchannels and the incipient bubble radius was measured accurately. Visualized images obtained for Case 4 at a frame rate of $4000 \mathrm{fps}$ during the first $400 \mathrm{~ms}$ of nucleate boiling are shown in Fig. 7 in which bubble nucleation, growth and departure are clearly identified. The radius of the bubble was measured as a function of time, and is plotted in Fig. 8. The first bubble captured in the images, such as the one in the first image of Fig. 7, is considered to be the incipient bubble. The measured incipient bubble radius is $10.24 \mu \mathrm{m}$ and indeed falls in the size range of 10 to 23.2 $\mu \mathrm{m}$ as predicted by the present model.

\subsection{Bubble Growth Subsequent to ONB}

Figure 8 also demonstrates that the bubble radius grows almost linearly after the ONB. The evolution curve can be represented by $r_{b}=0.075 t+11.6$, where the bubble radius is in $\mu \mathrm{m}$ and time is in ms. As noted earlier, it is expected that the contact angle will decrease as a function of time and reach its minimum at departure as the bubble grows. More quantitative information about the progression of the contact angle can be obtained based on this evolution curve. Continuing with the assumption that the bubble remains on the mouth of a nucleation cavity after inception, the contact angle can be estimated from Eq. (13) as

$$
\theta(t)=\sin ^{-1}\left[\frac{r_{c}}{r_{b}(t)}\right]
$$

For the current case (Case 4), taking $r_{c}=r_{b}=10 \mu \mathrm{m}$ and $\theta_{0}=90$ deg as the incipient values, the calculated contact angle progression is predicted and plotted as a function of time in Fig. 8. In contrast with the linear increase in the bubble radius, the contact angle is seen to decrease almost exponentially as time elapses.

\subsection{Parametric Study}

The effects of the different governing parameters on the incipient heat flux can be explored on the basis of Eq. (27). These parameters include flow conditions (inlet velocity $\mathrm{u}_{0}$, inlet temperature $\mathrm{T}_{\mathrm{f}, \text { in }}$ and 
exit pressure $\mathrm{P}_{\text {exit }}$ ) and microchannel dimensions (channel width $\mathrm{w}_{\mathrm{c}}$ and height $\mathrm{H}_{\mathrm{c}}$ ). It may be noted that the $y$-axis scale is identical in four of the five plots in Fig. 9; the exception is Fig. 9(b) which covers a larger range. It is clear from Fig. 9(a) to (e) that, increasing the flow rate, exit pressure and microchannel height will result in larger incipient heat fluxes, while increasing fluid inlet temperature and microchannel width causes a lower heat flux to initiate the ONB. Among these factors, the fluid inlet temperature seems to be the most influential over the typically possible operational ranges. The opposing trends of variation of incipient heat flux with microchannel width and height suggest that a higher channel aspect ratio (height to width) will retard the ONB. This comes as a consequence of the more efficient transfer of heat from the channel wall to the bulk fluid due to the larger Nusselt number (Eq. (19)) and therefore a lower wall temperature, as indicated by Eq. (18).

\section{CONCLUSIONS}

The onset of nucleate boiling in a microchannel heat sink was investigated experimentally and the incipient heat flux was measured for various flow conditions. A high-speed imaging system was employed to visualize the bubble evolution during the nucleate boiling. An analytical model was formulated to predict important parameters at the onset of nucleate boiling. In conjunction with explicit relations for convective heat transfer in microchannel flow, the functional dependence of incipient heat flux on fluid inlet velocity and subcooling, contact angle, microchannel dimensions and fluid exit pressure is accounted for in the proposed model. The model predicts the incipient heat flux for given fluid inlet conditions as well as the bubble size at the ONB. The closed-form solutions derived enable a straightforward interpretation of the parametric variations, and would be useful for practical design implementation. The model predictions show good agreement with both the experimental measurements and the boiling visualizations. 


\section{Acknowledgement}

The authors acknowledge the financial support from members of the Cooling Technologies Research Center (www.ecn.purdue.edu/CTRC), a National Science Foundation Industry/University Cooperative Research Center at Purdue University.

\section{Appendix: Derivation of superheat equation}

The temperature and pressure of the fluid and the vapor in a boiling system are depicted in Fig. A1. Since thermodynamic equilibrium is assumed during phase change, the vapor temperature $T_{b}$ and pressure $\mathrm{p}_{\mathrm{b}}$ can be represented by point $\mathrm{B}$ on the saturation curve on the $\mathrm{p}-\mathrm{T}$ plot. When nucleate boiling occurs, the surrounding fluid must be superheated and therefore, it is not in a saturated state. The temperature and pressure cannot be represented by a single point in the above plot. Instead, point A denotes the fluid pressure $\mathrm{P}_{\mathrm{f}}$ and the corresponding saturation temperature $\mathrm{T}_{\mathrm{s}}\left(\mathrm{P}_{\mathrm{f}}\right)$; point $\mathrm{B}$ marks the fluid temperature $T_{f}$ and the corresponding saturation pressure $P_{s}\left(T_{f}\right)$.

According to the Clapeyron equation, the slope of any point on the saturation curve can be written as

$$
\frac{d p}{d T}=\frac{h_{f g}}{T\left(v_{g}-v_{f}\right)} \approx \frac{h_{f g} \rho_{v}}{T}
$$

For the vapor phase, the ideal law states that $\rho_{v}=p /(R T)$. Hence, Eq. (A.1) becomes the ClapeyronClausius equation

$$
\frac{d p}{p}=\frac{h_{f g} d T}{R T^{2}}
$$

It may be noted that the Clapeyron-Clausius equation only holds in case of thermodynamic equilibrium. Therefore, any integration of Eq. (A.2) must be between two states on the saturation curve, for instance, from point $\mathrm{A}$ to $\mathrm{B}$ :

$$
\int_{p_{f}}^{p_{b}} \frac{d p}{p}=\int_{T_{s}\left(p_{f}\right)}^{T_{b}} \frac{h_{f g} d T}{R T^{2}}
$$


which gives

$$
\ln \left(\frac{p_{b}}{p_{f}}\right)=\frac{h_{f g}}{R}\left(\frac{1}{T_{s}\left(p_{f}\right)}-\frac{1}{T_{b}}\right)
$$

Then,

$$
\left[T_{b}-T_{s}\left(p_{f}\right)\right]=\frac{R T_{s}\left(p_{f}\right) T_{b}}{h_{f g}} \ln \left(\frac{p_{b}}{p_{f}}\right)
$$

The Young-Laplace equation describes the mechanical equilibrium at the vapor-liquid interface,

$$
p_{b}-p_{f}=2 \sigma / r_{b}
$$

Equation (A.5) can be re-arranged as

$$
\left[T_{b}-T_{s}\left(p_{f}\right)\right]=\frac{R T_{s}\left(p_{f}\right) T_{b}}{h_{f g}} \ln \left(1+\frac{2 \sigma}{r_{b} p_{f}}\right)
$$

which can be further simplified, since $1>>\frac{2 \sigma}{r_{b} p_{f}}$,

$$
\left[T_{b}-T_{s}\left(p_{f}\right)\right]=\frac{R T_{s}\left(p_{f}\right) T_{b}}{h_{f g}} \frac{2 \sigma}{r_{b} p_{f}}
$$

Again, if applying the ideal gas law at point A (since $\rho_{v}=p_{f} /\left[R T_{s}\left(p_{f}\right)\right]$ ), Eq. (A.8) becomes

$$
\left[T_{b}-T_{s}\left(p_{f}\right)\right]=\frac{T_{b}}{\rho_{v} h_{f g}} \frac{2 \sigma}{r_{b}}
$$

\section{REFERENCES}

[1] Sobhan, C. B. and Garimella, S. V, 2001, "A comparative analysis of studies on heat transfer and fluid flow in microchannels," Microscale Thermophysical Eng., Vol. 5, pp. 293-311.

[2] Kandlikar, S. G., 2002, "Fundamental issues related to flow boiling in minichannels and microchannels," Experimental Thermal and Fluid Science, Vol. 26, pp. 389-407. 
[3] Bergles, A. E., Lienhard, V. J. H., Kendall, G. E., and Griffith, P., 2003, "Boiling and evaporation in small diameter channels" Heat Transfer Engineering, Vol. 24, pp. 18-40.

[4] Thome, J. R., 2004, "Boiling in microchannels: a review of experiment and theory,” Int. J. Heat Fluid Flow, Vol.25, pp. 128-139.

[5] Ghiaasiaan, S. M., and Chedester, R. C., 2002, "Boiling incipience in microchannels," Int. J. Heat Mass Transfer, Vol. 45, pp. 4599-4606.

[6] Hsu, Y. Y., 1962, “On the size range of active nucleation cavities on a heating surface," J. Heat Transfer, Vol. 84, pp. 207-216.

[7] Sato, T. and Matsumura, H., 1963, "On the conditions of incipient subcooled-boiling with forced convection,” Bull. JSME, Vol. 7, pp. 392-398.

[8] Bergles, A. E., and Rohsenow, W. M., 1964, "The determination of forced-convection surfaceboiling heat transfer," J. Heat Transfer, Vol. 86, pp. 365-372.

[9] Davis, E. J., and Anderson, G. H., 1966, "The incipience of nucleate boiling in forced convection flow," AIChE Journal, Vol. 12, pp. 774-780.

[10] Kandlikar, S. G., Mizo, V., Cartwright, M., and Ikenze, E., 1997, "Bubble nucleation and growth characteristics in subcooled flow boiling of water," National Heat Transfer Conference, ASME, HTD-342, pp. 11-18.

[11] Celata, G. P., Cumo, M., and Mariani, A., 1997, "Experimental evaluation of the onset of subcooled flow boiling at high liquid velocity and subcooling,” Int. J. Heat Mass Transfer, Vol. 40, pp. 28792885.

[12] Basu, N., Warrier, G. R., and Dhir, V. K., 2002, "Onset of nucleate boiling and active nucleation site density during subcooled flow boiling,” J. Heat Transfer, Vol. 124, pp. 717-728.

[13] Qu, W., and Mudawar, I., 2002, "Prediction and measurement of incipient boiling heat flux in microchannel heat sinks,” Int. J. Heat Mass Transfer, Vol. 45, pp. 3933-3945. 
[14] Li, J., and Cheng, P., 2004, "Bubble cavitation in a microchannel," Int. J. Heat Mass Transfer, Vol. 47, pp. 2689-2698.

[15] Thom, J. R. S., Walker, W. M., Fallon, T. A., and Reising, G. F. S., 1965, “Boiling in subcooled water during flow up heated tubes or annuli," Symposium on Boiling Heat Transfer in Steam Generating Units and Heat Exchangers, Manchester, September, London.

[16] Steinke, M. E. and Kandlikar, S. G., 2004, "Control and effect of dissolved air in water during flow boiling in microchannels,” Int. J. Heat Mass Transfer, Vol. 47, pp. 1925-1935.

[17] Taylor, J. R., 1997, An Introduction to Error Analysis, University Science Books.

[18] Kandlikar, S. G., and Stumm, B., J., 1995, "A control volume approach for investigating forces on a departing bubble under subcooled flow boiling,” J. Heat Transfer, Vol. 117, pp. 990-997.

[19] Shah, R. K. and London, A. L., 1978, "Laminar flow forced convection in ducts," Supplement 1, Adv. Heat Transfer.

[20] Liu, D., and Garimella, S. V., 2005, “Optimization of the thermal performance of microchannel heat sinks," Int. J. Numerical Methods for Heat Fluid Flow, Vol. 15, pp.7-26.

[21] Lee, P. S., Garimella, S. V., and Liu, D., 2005, "Investigation of heat transfer in rectangular microchannels,” Int. J. Heat Mass Transfer, Vol. 48, pp. 1688-1704.

[22] Fedorov, A., and Viskanta, R., 2000, “Three-dimensional conjugate heat transfer in the microchannel heat sink for electronic packaging,” Int. J. Heat Mass Transfer, Vol. 43, pp. 399-415.

[23] Shakir, S. and Thome, J. R., 1986, "Boiling nucleation of mixtures on smooth and enhanced surfaces," the 8th Int. Heat Transfer Conf., Vol. 4, pp. 2081-2086, San Francisco.

[24] Lee, P. C., Tseng, F. G., and Pan, C., 2004, "Bubble dynamics in microchannels. Part I: Single microchannel,” Int. J. Heat Mass Transfer, Vol. 47, pp. 5575-5589.

[25] Lee, P. C., Tseng, F. G., and Pan, C., 2004, "Bubble dynamics in microchannels. Part II: Two parallel microchannels,” Int. J. Heat Mass Transfer, Vol. 47, pp. 5591-5601. 
Table 1. Studies in the literature of ONB in subcooled flow boiling.

\begin{tabular}{|c|c|c|c|}
\hline Reference & Key Assumptions & Model Development & Proposed ONB Correlation \\
\hline \multicolumn{4}{|c|}{ Past work for conventional-sized channels } \\
\hline Hsu [6] & $\begin{array}{l}\text { - Limiting thermal layer exists } \\
\text { below which molecular transport } \\
\text { prevails. } \\
\text { - Bubble nucleus will grow when } \\
\text { superheat criterion is satisfied at } \\
\text { the distance of one bubble } \\
\text { diameter from the wall. }\end{array}$ & $\begin{array}{l}\text { - Solve the transient-conduction problem. } \\
\text { - ONB occurs when the transient temperature } \\
\text { meets the superheat criterion. } \\
\text { - Only cavities within a size range can be } \\
\text { active. }\end{array}$ & $q_{O N B}^{\prime \prime}=\frac{k_{f} h_{f g} \rho_{v}\left(T_{w}-T_{s a t}\right)^{2}}{12.8 \sigma T_{s a t}}$ \\
\hline $\begin{array}{l}\text { Sato and } \\
\text { Matsumara [7] }\end{array}$ & $\begin{array}{l}\text { - Spherical bubble nucleus obtains } \\
\text { thermal energy indirectly from the } \\
\text { surrounding liquid. }\end{array}$ & $\begin{array}{l}\text { - Critical bubble radius is determined by } \\
\text { solving the equation of the thickness of } \\
\text { superheated layer. }\end{array}$ & $q_{O N B}^{\prime \prime}=\frac{k_{f} h_{f g} \rho_{v}\left(T_{w}-T_{s a t}\right)^{2}}{8 \sigma T_{s a t}}$ \\
\hline $\begin{array}{l}\text { Bergles and } \\
\text { Rohsenow [8] }\end{array}$ & $\begin{array}{l}\text { - Hemispherical bubble nucleus will } \\
\text { grow when the superheat criterion } \\
\text { is satisfied at the distance of one } \\
\text { bubble radius from the wall. } \\
\text { - Near-wall temperature of liquid is } \\
\text { approximated by a linear relation } \\
\text { (conduction). }\end{array}$ & $\begin{array}{l}\text { - ONB occurs when the liquid temperature } \\
\text { is tangent to the superheat curve. } \\
\text { - Graphical solution to predict incipient heat } \\
\text { flux for water over a pressure range of } 15 \\
\sim 2000 \text { psi. }\end{array}$ & $\begin{array}{l}q_{O N B}^{\prime \prime}=1082 p^{1.156}\left[1.8\left(T_{w}-T_{\text {sat }}\right)\right]^{2.16 / p^{0.0234}}(3) \\
\left(q^{\prime \prime \text { ONB }} \text { is in } \mathrm{W} / \mathrm{m}^{2}, p \text { is in bar and } T \text { in }{ }^{\circ} \mathrm{C}\right)\end{array}$ \\
\hline $\begin{array}{l}\text { Davis and } \\
\text { Anderson [9] }\end{array}$ & $\begin{array}{l}\text { - Hemispherical bubble nucleus will } \\
\text { grow when superheat criterion is } \\
\text { satisfied at the distance of one } \\
\text { bubble radius from the wall. }\end{array}$ & $\begin{array}{l}\text { - Tangent equations in [8] solved } \\
\text { analytically. }\end{array}$ & $q_{O N B}^{\prime \prime}=\frac{k_{f} h_{f g} \rho_{v}\left(T_{w}-T_{s a t}\right)^{2}}{8(1+\cos \theta) \sigma T_{s a t}}$ \\
\hline $\begin{array}{l}\text { Kandlikar et al. } \\
{[10]}\end{array}$ & $\begin{array}{l}\text { - Liquid temperature at the bubble } \\
\text { top equals that of the stagnation } \\
\text { point in the thermal boundary } \\
\text { layer. }\end{array}$ & $\begin{array}{l}\text { - Location of stagnation point was } \\
\text { calculated numerically. }\end{array}$ & $q_{O N B}^{\prime \prime}=\frac{k_{f} h_{f g} \rho_{v}\left(T_{w}-T_{s a t}\right)^{2}}{9.2 \sigma T_{s a t}}$ \\
\hline Celata et al. [11] & $\begin{array}{l}\text { - ONB occurs when experimental } \\
\text { data deviate from theoretical } \\
\text { prediction on a pressure vs. heat } \\
\text { flux plot. }\end{array}$ & - & $q_{O N B}^{\prime \prime}=0.00195\left(T_{w}-T_{s a t}\right)^{2} \exp (0.023 p)$ \\
\hline Basu et al. [12] & $\begin{array}{l}\text { - Size of available cavity is } \\
\text { proportional to that obtained from } \\
\text { superheat criterion. }\end{array}$ & $\begin{array}{l}\text { - Correction factor for cavity size obtained } \\
\text { from experiments. } \\
\text { - Superheat equation rewritten with } \\
\text { corrected cavity size. }\end{array}$ & $\begin{array}{l}q_{O N B}^{\prime \prime}=h_{s p}\left(T_{w}-T_{s a t}\right)+h_{s p}\left(T_{s a t}-T_{f}\right) \\
\left(T_{w}-T_{s a t}\right)=\frac{4 \sigma T_{s a t}}{D_{c} h_{f g} \rho_{v}}, D_{c}=F\left[\frac{8 \sigma T_{s a t} k_{f}}{h_{f g} \rho_{v} q_{w}^{\prime \prime}}\right]^{1 / 2} \\
F=1-\exp \left[-\left(\frac{\pi \theta}{180}\right)^{3}-0.5\left(\frac{\pi \theta}{180}\right)\right]\end{array}$ \\
\hline
\end{tabular}




\begin{tabular}{|c|c|c|c|}
\hline Reference & Key Assumptions & Model Development & Proposed ONB Correlation \\
\hline \multicolumn{4}{|c|}{ Recent work for microchannels } \\
\hline $\begin{array}{l}\text { Ghiaasiaan and } \\
\text { Chedester [5] }\end{array}$ & $\begin{array}{l}\text { - ONB occurs when thermocapillary } \\
\text { force balances aerodynamic } \\
\text { force. } \\
\text { - Shape factor of contact angle is } \\
\text { strongly dependent on the relative } \\
\text { magnitude of the two forces. }\end{array}$ & $\begin{array}{l}\text { - Semi-empirical method developed to } \\
\text { calculate the shape factor using channel } \\
\text { turbulence characteristics and } \\
\text { experimental data of incipient heat flux. } \\
\text { - Davis and Anderson's correlation } \\
\text { corrected with the obtained shape factor. }\end{array}$ & $\begin{array}{l}q_{O N B}^{\prime \prime}=\frac{k_{f} h_{f g} \rho_{v}\left(T_{w}-T_{s a t}\right)^{2}}{C \sigma T_{s a t}} \\
C=22 \xi^{0.765}, \xi=\frac{\sigma_{f}-\sigma_{w}}{\rho_{f} u_{0} R^{*}} \\
R^{*}=\left[\frac{2 \sigma T_{s} k_{f}}{q_{O N B} " \rho_{v} h_{f g}}\right]^{1 / 2}\end{array}$ \\
\hline $\begin{array}{l}\text { Qu and Mudawar } \\
{[13]}\end{array}$ & $\begin{array}{l}\text { - Bubble departs when } \\
\text { aerodynamic force overcomes } \\
\text { surface tension. } \\
\text { - Bubble will grow when the } \\
\text { temperature at the tip exceeds } \\
\text { saturation temperature. }\end{array}$ & $\begin{array}{l}\text { - Bubble departure radius obtained from a } \\
\text { mechanical force balance. } \\
\text { - Fluid temperature calculated numerically } \\
\text { from a 2-D model; if the lowest } \\
\text { temperature at bubble interface exceeds } \\
\text { saturation temperature, ONB is deemed to } \\
\text { occur. }\end{array}$ & $\begin{array}{l}\text { An iterative procedure proposed to calculate } \\
q_{O N B} " .\end{array}$ \\
\hline Li and Cheng [14] & $\begin{array}{l}\text { - Bubble will grow when the } \\
\text { temperature at the tip exceeds } \\
\text { nucleation temperature. }\end{array}$ & $\begin{array}{l}\text { - Fluid nucleation temperature obtained } \\
\text { from classical nucleation kinetics theory, } \\
\text { and used in place of saturation } \\
\text { temperature. } \\
\text { - Effect of dissolved gas incorporated in the } \\
\text { vapor pressure term in the model. }\end{array}$ & - \\
\hline
\end{tabular}


Table 2. Experimental parameters.

\begin{tabular}{|c|c|c|c|c|c|c|c|c|}
\hline Case & $\begin{array}{c}\mathbf{u}_{0} \\
(\mathbf{m} / \mathbf{s})\end{array}$ & $\mathbf{R e}$ & $\begin{array}{c}\mathbf{G} \\
\left(\mathbf{k g} / \mathbf{s} \mathbf{~ m}^{2}\right)\end{array}$ & $\begin{array}{l}\mathrm{T}_{\mathrm{f}, \mathrm{in}} \\
\left({ }^{\circ} \mathrm{C}\right)\end{array}$ & $\begin{array}{l}P_{\text {exit }} \\
(\mathrm{Pa})\end{array}$ & $\begin{array}{l}\text { q"'boiling viz } \\
\left(\mathrm{W}^{2} / \mathrm{cm}^{2}\right)\end{array}$ & $\begin{array}{c}\mathbf{q}^{\prime \prime} \exp \\
\text { from } \\
\text { measured } \\
\text { temp, } \\
\text { pressure } \\
\left(\mathbf{W} / \mathbf{c m}^{2}\right)\end{array}$ & $\begin{array}{l}\text { q"model } \\
\left(\mathbf{W} / \mathrm{cm}^{2}\right)\end{array}$ \\
\hline 1 & 0.52 & 569 & 498 & 84.9 & 102966 & 14.28 & 14.65 & 15.32 \\
\hline 2 & 0.56 & 662 & 544 & 90.2 & 107523 & 10.71 & 10.07 & 12.59 \\
\hline 3 & 0.61 & 682 & 586 & 86.3 & 103366 & 13.22 & 14.28 & 15.80 \\
\hline 4 & 0.65 & 731 & 626 & 86.5 & 103393 & 15.80 & 15.78 & 16.16 \\
\hline 5 & 0.76 & 866 & 726 & 87.1 & 104145 & 15.34 & 17.67 & 17.02 \\
\hline 6 & 0.83 & 945 & 799 & 87.6 & 97844 & 14.45 & 14.74 & 15.15 \\
\hline 7 & 0.87 & 993 & 839 & 87.6 & 104620 & 16.71 & 17.90 & 17.82 \\
\hline 8 & 0.92 & 1050 & 883 & 87.9 & 107302 & 15.80 & 16.94 & 18.79 \\
\hline 9 & 0.51 & 464 & 494 & 71.1 & 103765 & 22.85 & 26.35 & 27.59 \\
\hline 10 & 0.55 & 501 & 536 & 70.9 & 104469 & 28.87 & 31.37 & 29.18 \\
\hline 11 & 0.63 & 572 & 610 & 71.1 & 102387 & 27.92 & 30.16 & 30.53 \\
\hline 12 & 0.76 & 699 & 742 & 71.3 & 103917 & 31.85 & 32.50 & 33.79 \\
\hline 13 & 0.82 & 759 & 803 & 71.6 & 103828 & 31.93 & 35.64 & 34.72 \\
\hline 14 & 0.91 & 699 & 899 & 57.9 & 107157 & 51.56 & 52.61 & 52.99 \\
\hline 15 & 0.82 & 759 & 804 & 71.6 & 104338 & 33.42 & 37.33 & 34.38 \\
\hline 16 & 0.32 & 288 & 309 & 70.6 & 103924 & 20.63 & 21.96 & 21.87 \\
\hline 17 & 0.54 & 644 & 521 & 91.5 & 102849 & 9.88 & 10.88 & 10.46 \\
\hline 18 & 0.76 & 907 & 730 & 92.0 & 103876 & 10.56 & 11.45 & 11.95 \\
\hline 19 & 0.76 & 583 & 746 & 58.2 & 103476 & 51.93 & 54.43 & 56.39 \\
\hline 20 & 0.63 & 487 & 622 & 58.3 & 103145 & 47.02 & 47.98 & 53.47 \\
\hline 21 & 0.51 & 392 & 502 & 58.1 & 102242 & 39.23 & 38.90 & 44.70 \\
\hline 22 & 0.76 & 454 & 756 & 41.2 & 103965 & 68.81 & 73.16 & 76.78 \\
\hline 23 & 0.52 & 309 & 514 & 41.3 & 102421 & 60.73 & 61.97 & 66.07 \\
\hline
\end{tabular}




\section{LIST OF FIGURE CAPTIONS}

Figure 1. Schematic of the experimental apparatus: (a) test loop; (b) 3D view of the microchannel test section (to scale), and (c) cross-section of test section (not to scale).

Figure 2. Onset of nucleate boiling: (a) bubble nucleus at incipience, and (b) ONB superheat criterion.

Figure 3. Visualization of bubbles at ONB (for example Case 10).

Figure 4. Comparison of model predictions of incipient heat flux against: (a) experimental results from the present work, and (b) experimental data from [13].

Figure 5. Comparison of predictions of wall superheat as a function of incipient heat flux from the present model as well as those from the literature [6, 7, 9-11].

Figure 6. (a) Nucleation cavity size for the sample Case 4, and (b) predicted values of the incipient bubble radius.

Figure 7. Visualization of the nucleate boiling process in a microchannel (4000 fps, for sample Case 4).

Figure 8. Evolution of bubble radius and calculated contact angle (for sample Case 4).

Figure 9. Effects of various parameters on incipient heat flux: (a) flow rate, (b) inlet temperature, (c) exit pressure, (d) channel width, and (e) channel height.

Figure A1. (a) Boiling system, and (b) p-T relation of vapor bubble at equilibrium. 


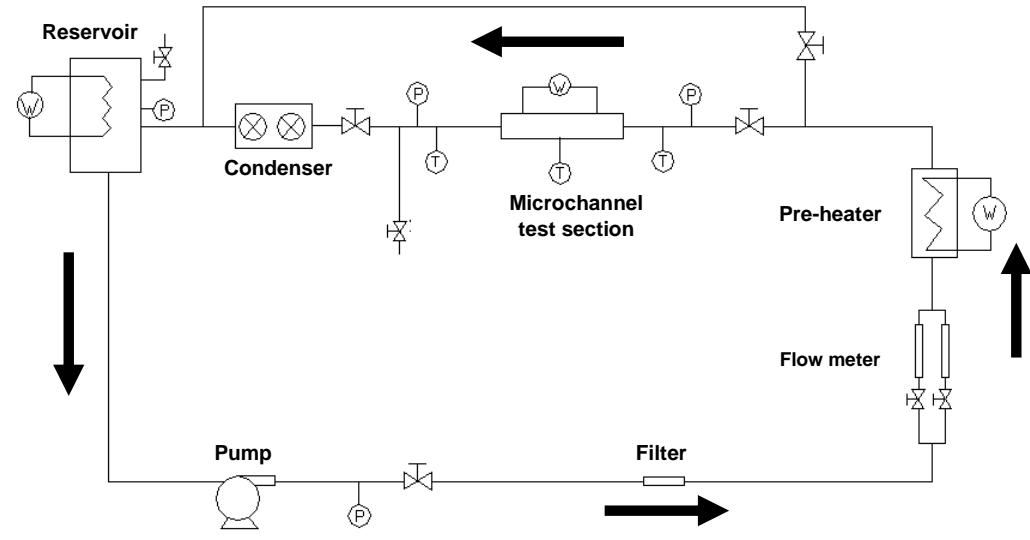

(a)

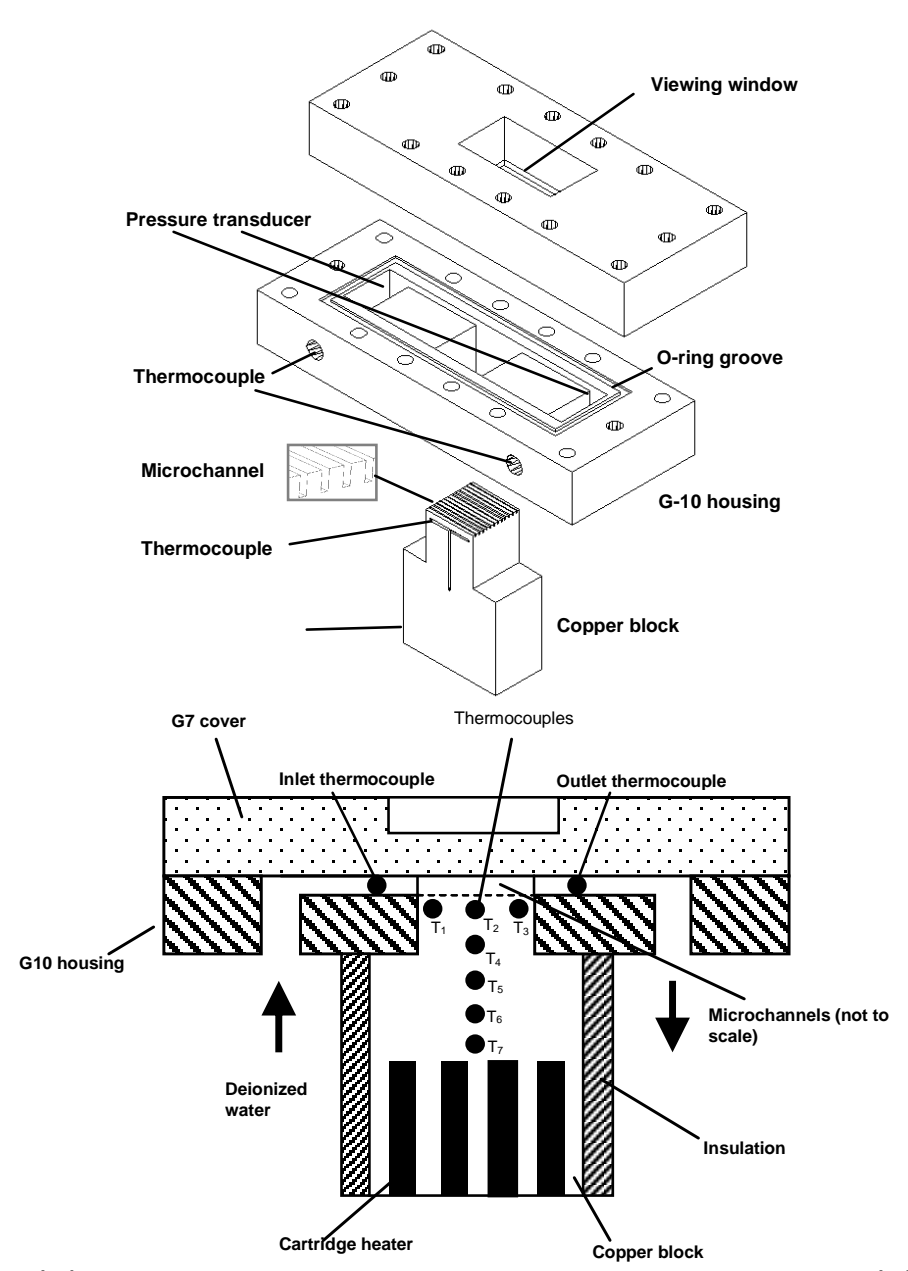

(b)

(c)

Figure 1. Schematic of the experimental apparatus: (a) test loop; (b) 3D view of the microchannel test section (to scale), and (c) cross-section of test section (not to scale). 


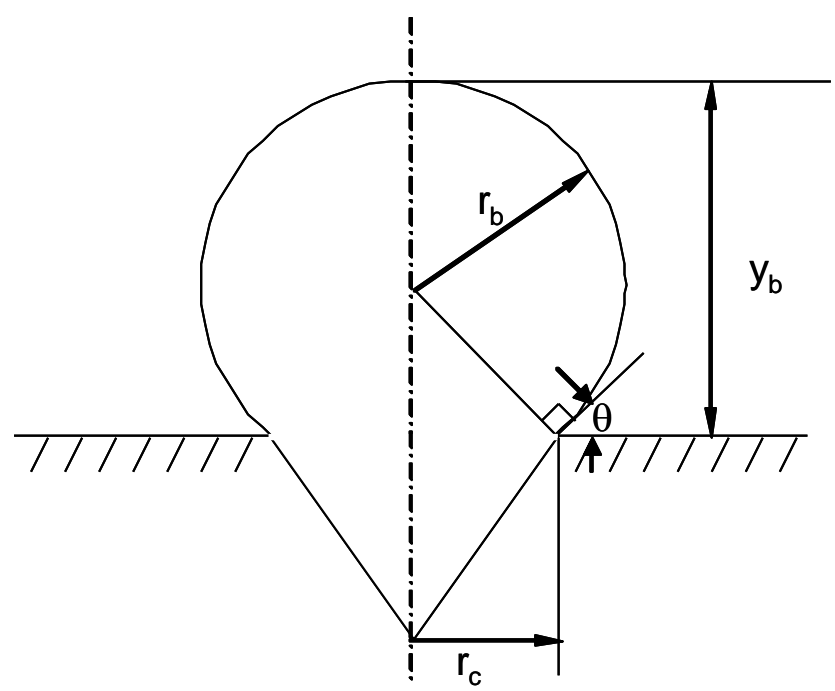

(a)

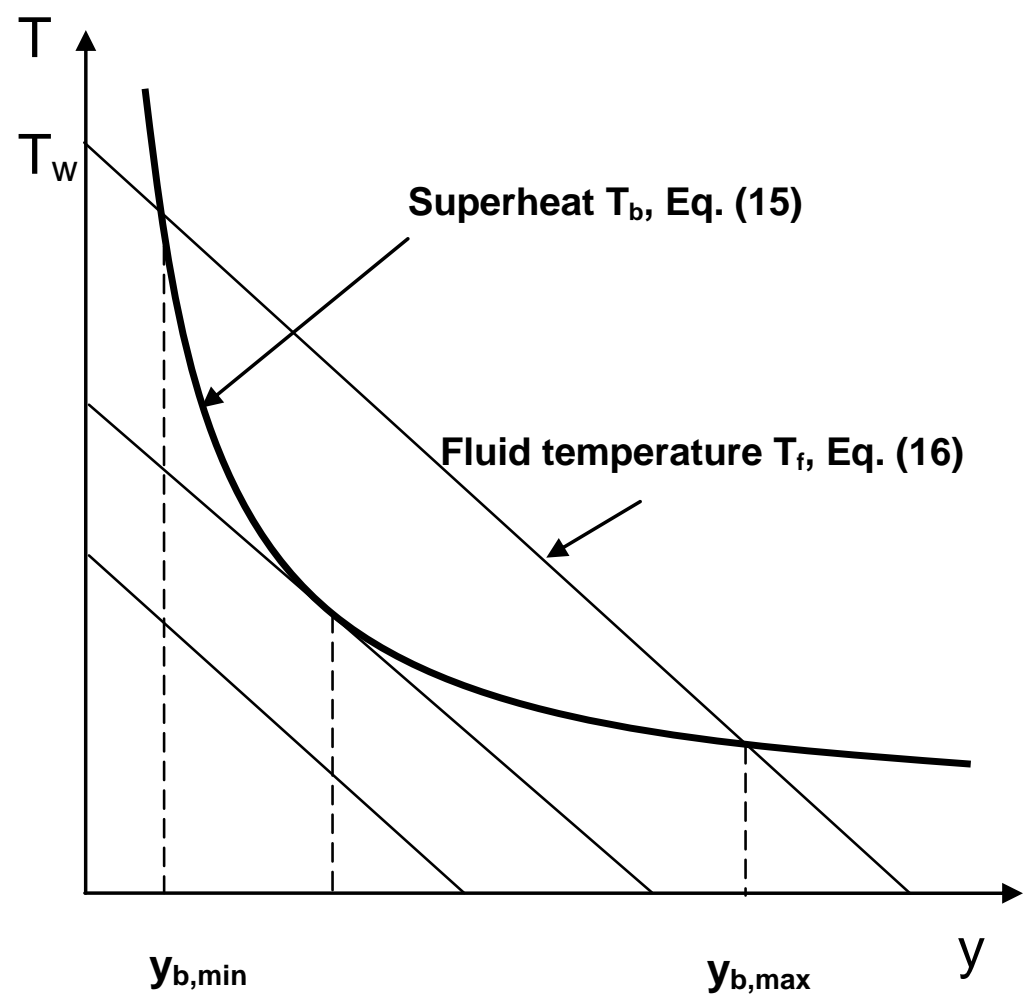

(b)

Figure 2. Onset of nucleate boiling: (a) bubble nucleus at incipience, and (b) ONB superheat criterion. 


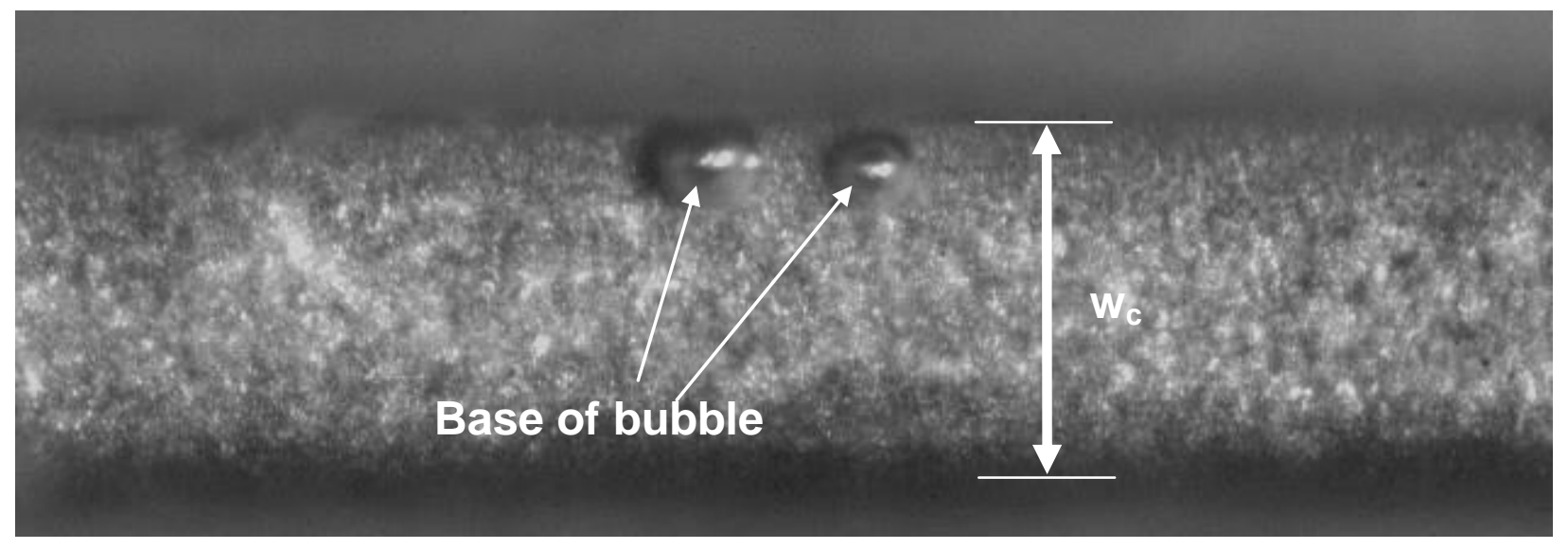

Figure 3. Visualization of bubbles at ONB (for example Case 10). 


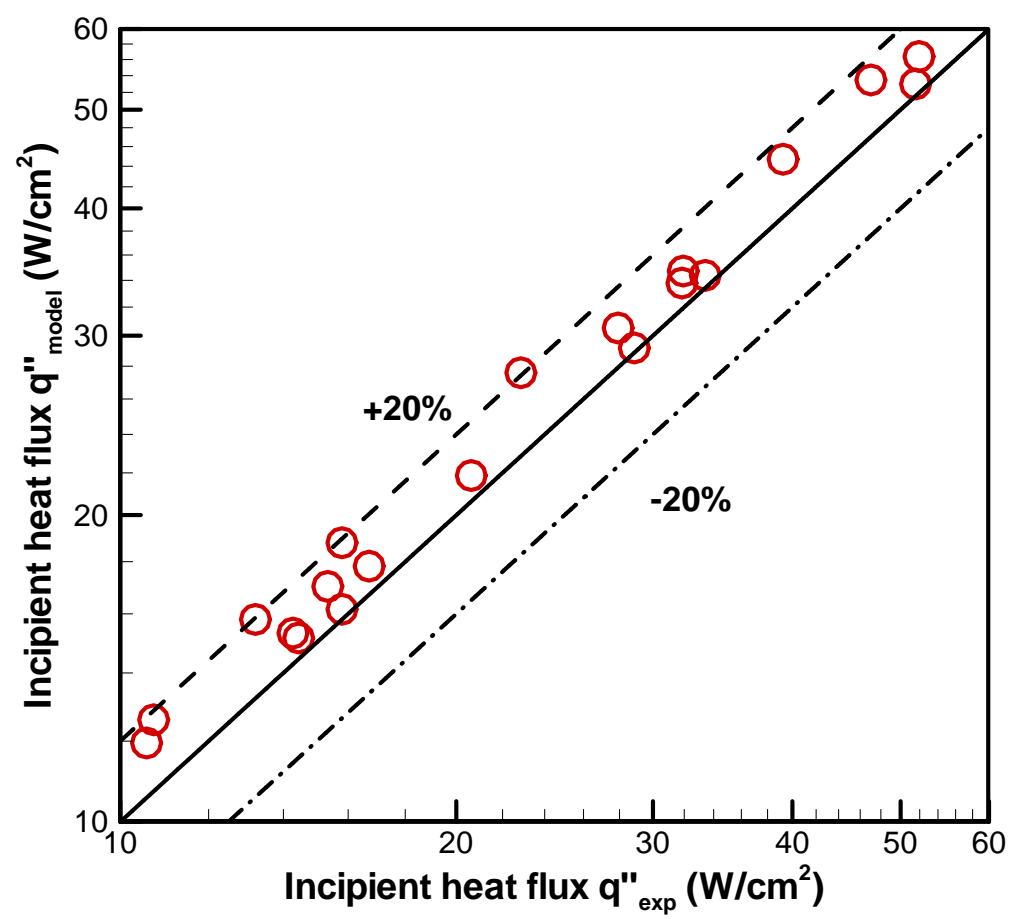

(a)

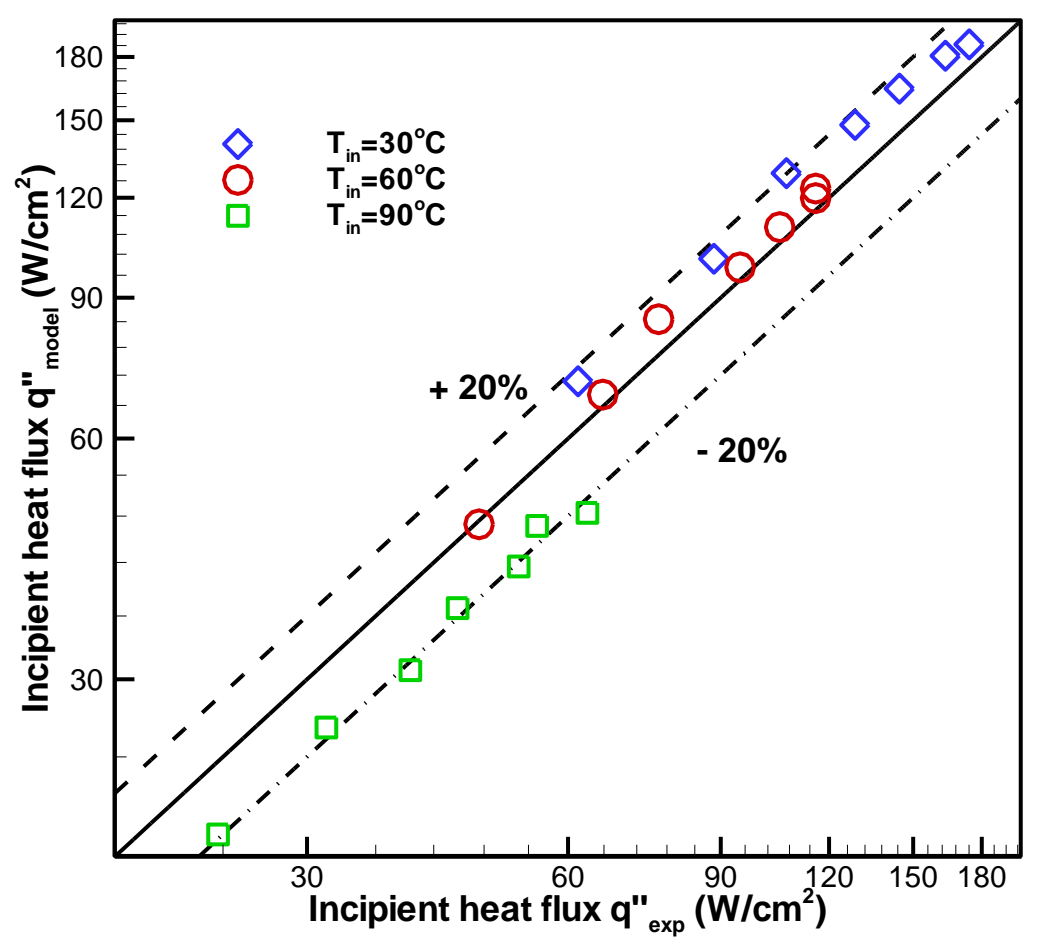

(b)

Figure 4. Comparison of model predictions of incipient heat flux against: (a) experimental results from the present work, and (b) experimental data from [13]. 


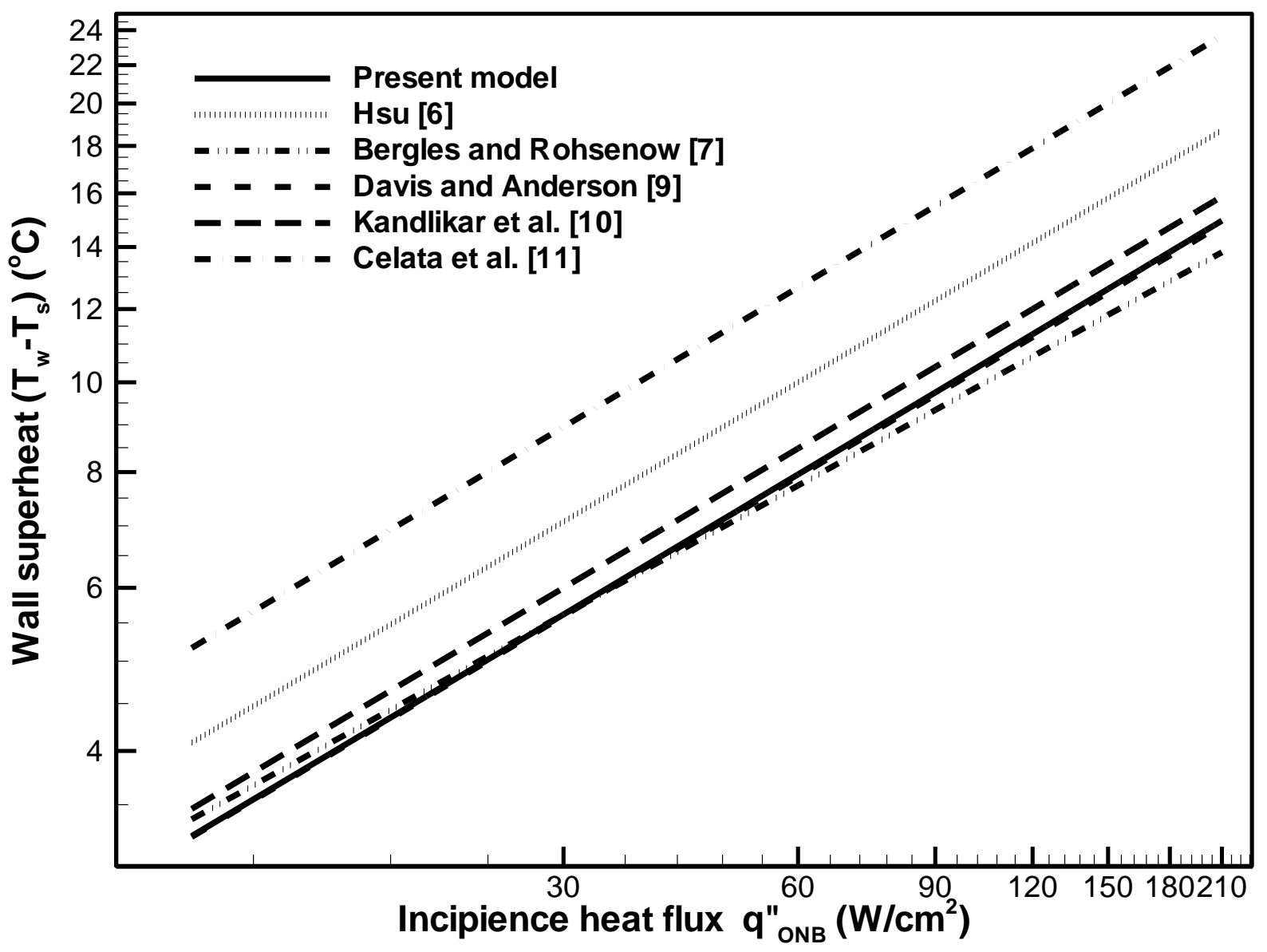

Figure 5. Comparison of predictions of wall superheat as a function of incipient heat flux from the present model as well as those from the literature [6, 7, 9-11]. 


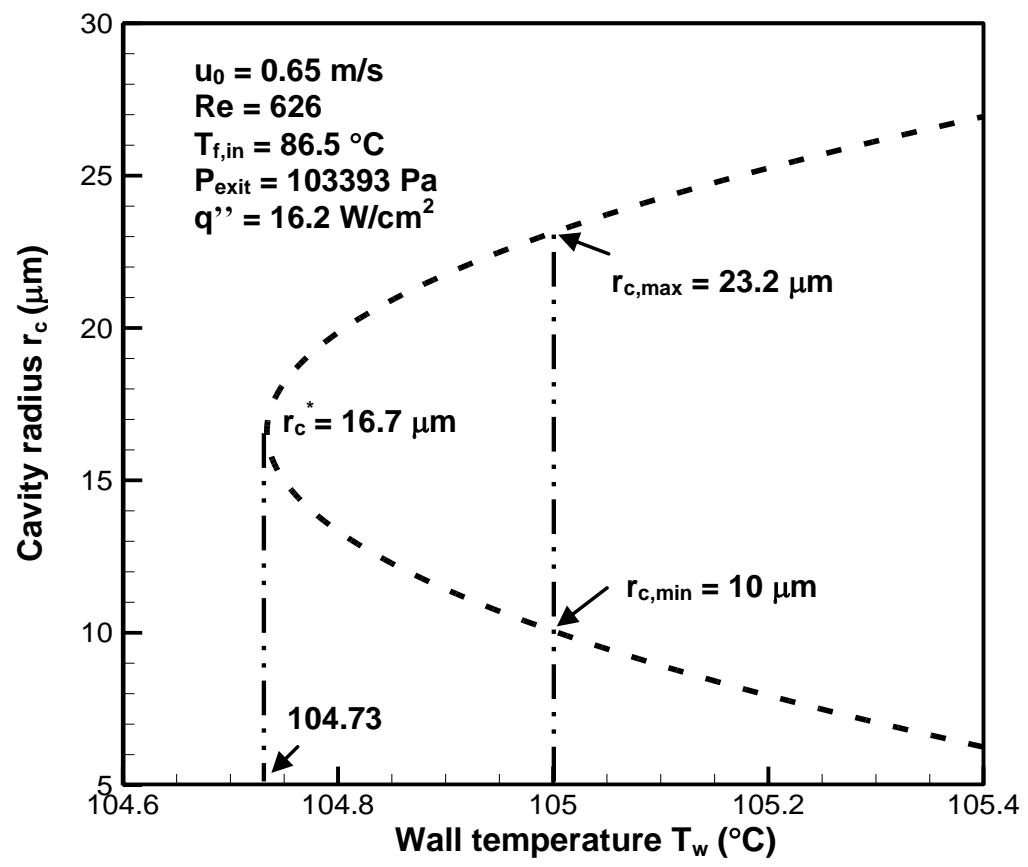

(a)

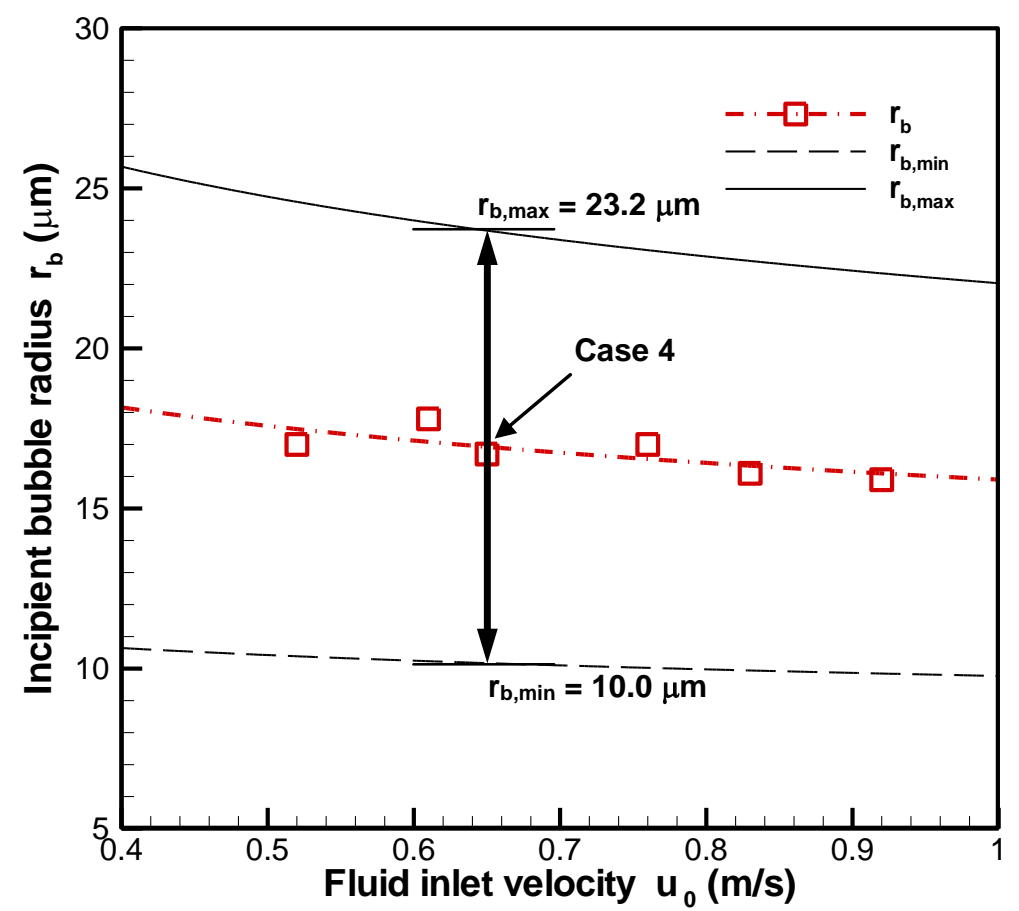

(b)

Figure 6. (a) Nucleation cavity size for the sample Case 4, and (b) predicted values of the incipient bubble radius. 


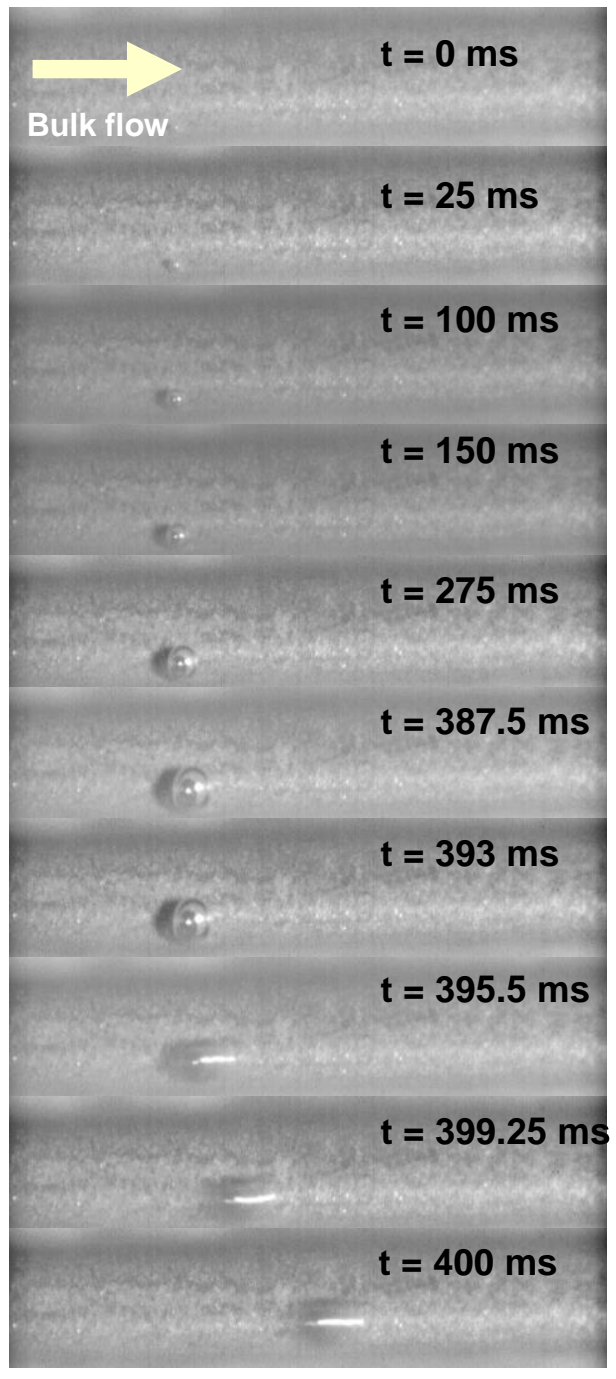

Figure 7. Visualization of the nucleate boiling process in a microchannel (4000 fps, for sample Case 4). 


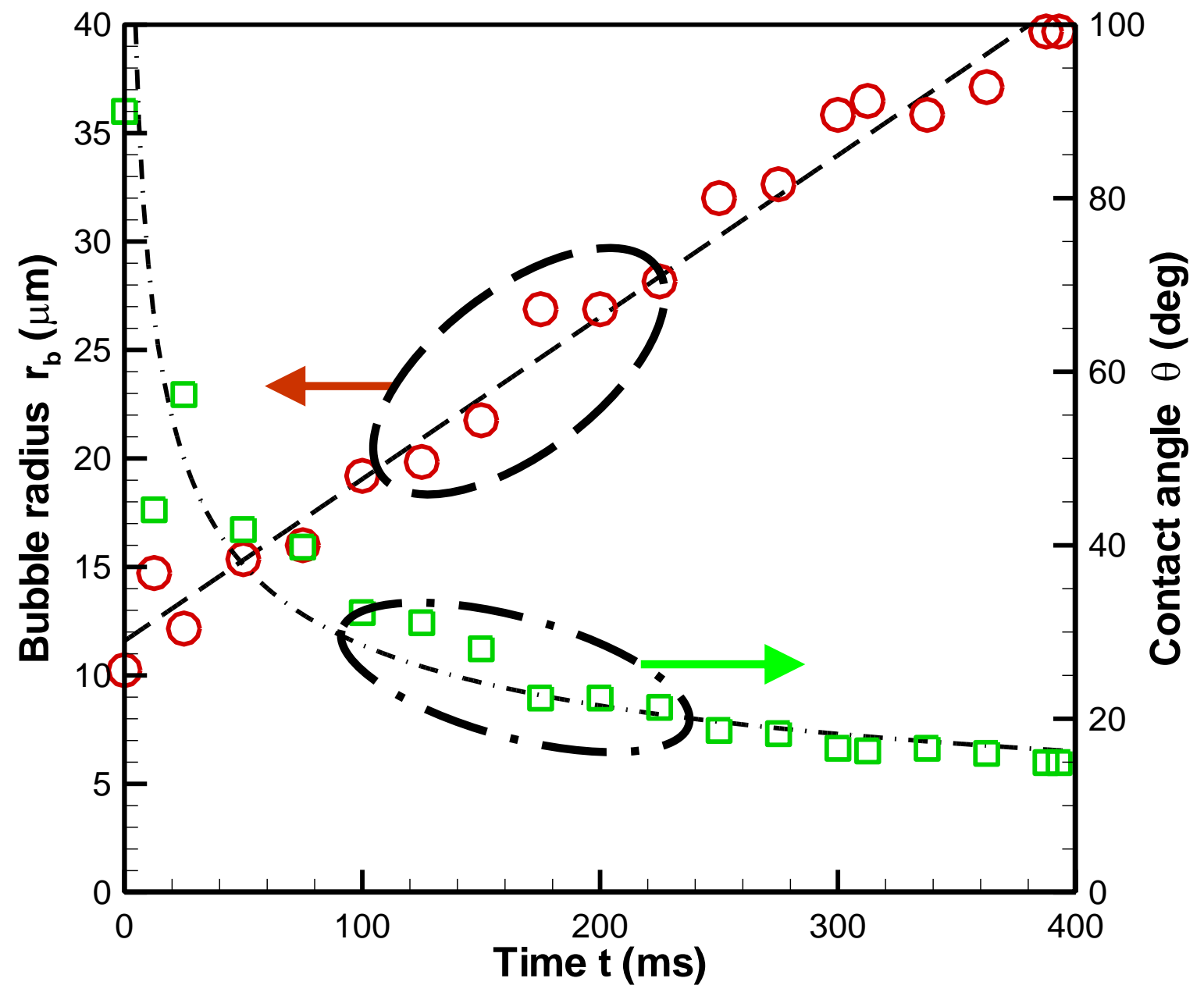

Figure 8. Evolution of bubble radius and calculated contact angle (for sample Case 4). 


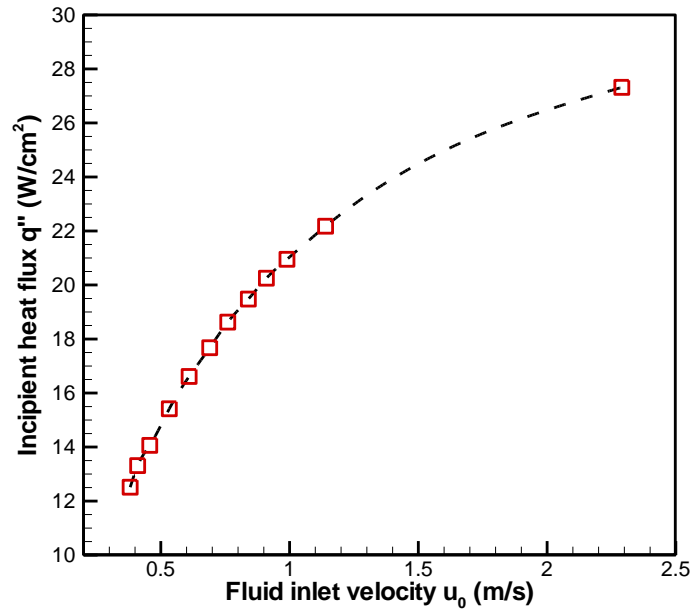

(a)

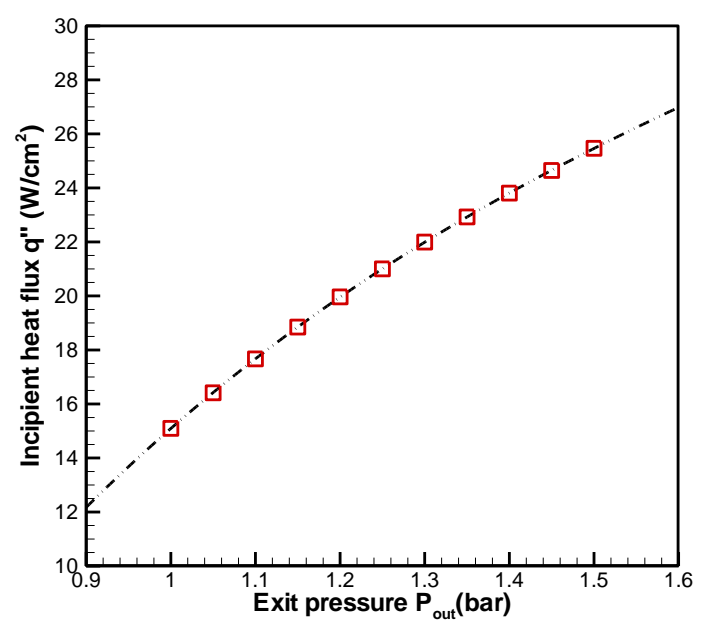

(c)

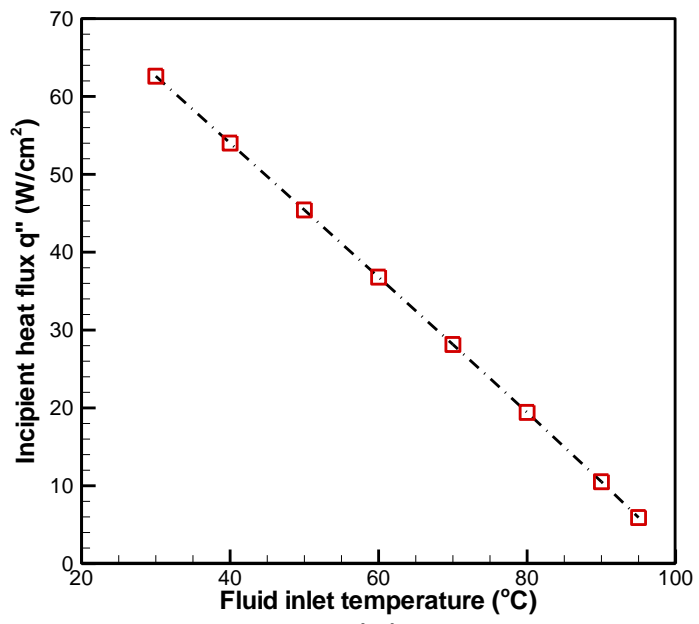

(b)

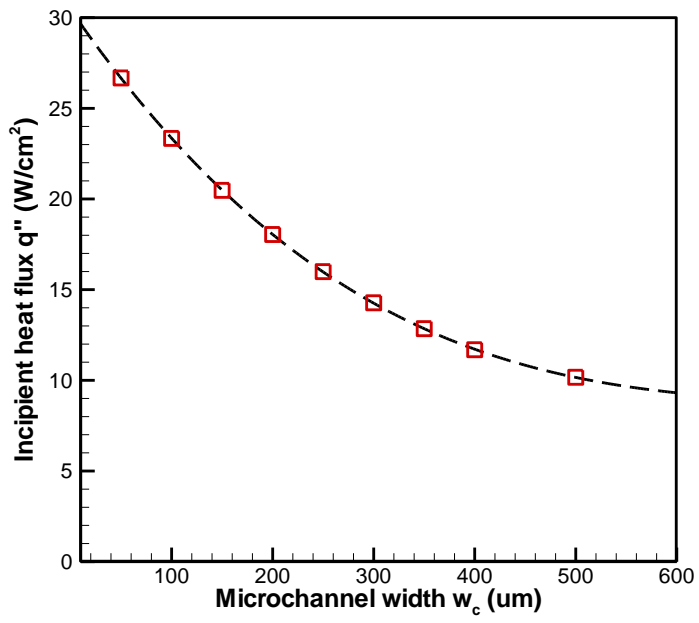

(d)

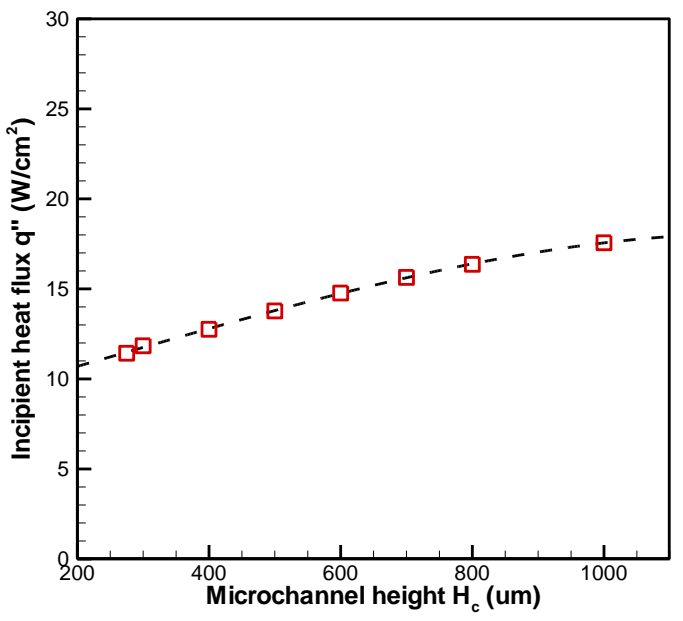

(e)

Figure 9. Effects of various parameters on incipient heat flux: (a) flow rate, (b) inlet temperature, (c) exit pressure, (d) channel width, and (e) channel height. 


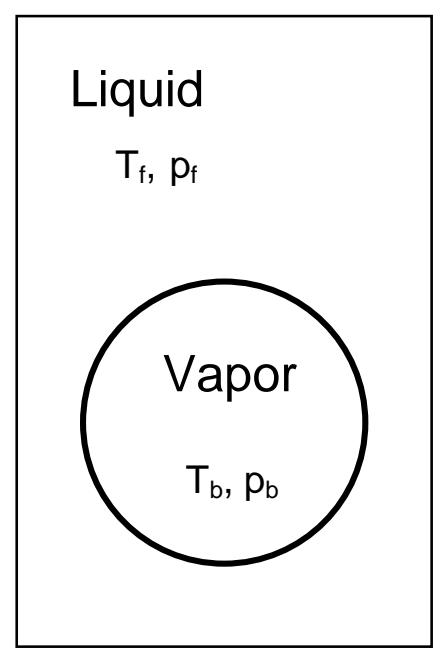

(a)

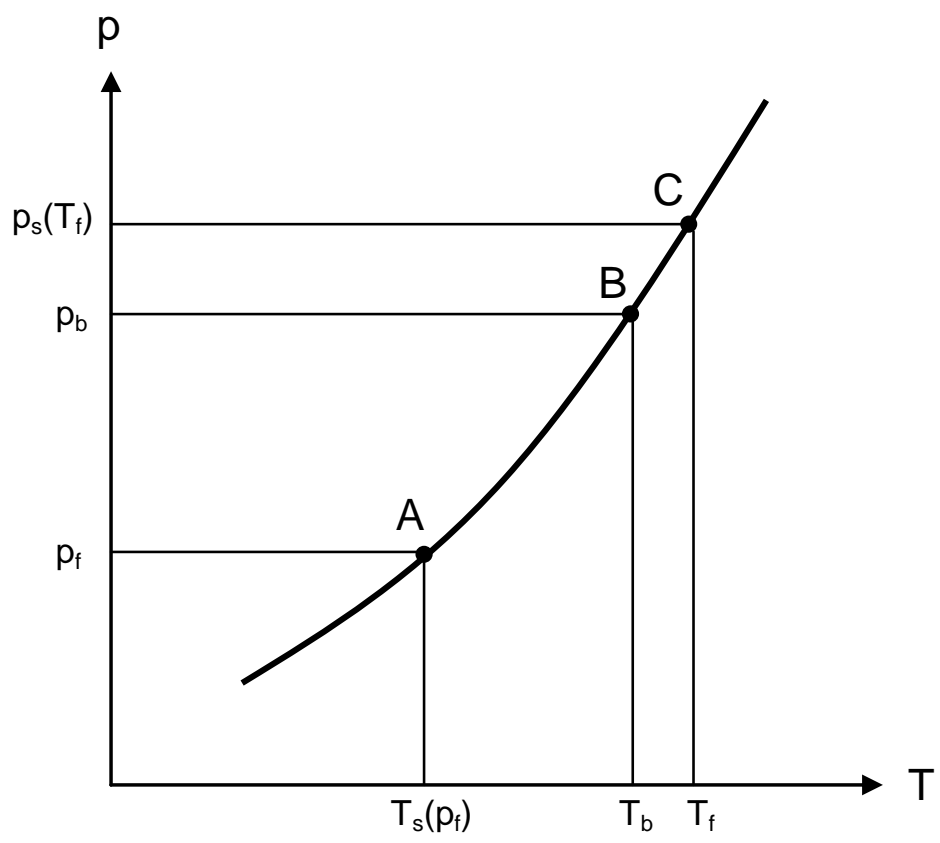

(b)

Figure A1. (a) Boiling system, and (b) p-T relation of vapor bubble at equilibrium. 